\title{
Iron and Microbial Growth
}

\author{
Argiris Symeonidis ${ }^{1}$ and Markos Marangos ${ }^{2}$ \\ ${ }^{1}$ Hematology Division and \\ ${ }^{2}$ Division of Infectious Diseases, \\ Dept of Internal Medicine, University of Patras Medical School, Patras,
}

Greece

\section{Introduction}

Iron is an essential element for the growth and development of all the scale of living organisms, and acquiring iron is crucial for the development of any pathogen. Iron participates in a large number of cellular processes, the most important of which are oxygen transport, ATP generation, cell growth and proliferation, and detoxification. It is a coenzyme or enzyme activator of ribonucleotide reductase, a key enzyme for DNA synthesis, which catalyzes the conversion of ribonucleotides to deoxyribonucleotidides and particularly of deoxyuridine to thymidine. ${ }^{1}$

Iron is essential for both, the pathogen and the host, and complex mechanisms have evolved that illustrate the longstanding battle between pathogens and hosts for iron acquisition. The host has developed mechanisms to withhold iron from the microorganisms, thus preventing their growth, while the microorganisms have the capacity to adapt to the iron restricted environment by several strategies. Furthermore, iron modulates immune effector mechanisms, such as cytokine activities, nitric oxide (NO) formation or immune cell proliferation, and consequently, host immune surveillance. ${ }^{2}$ High levels of free iron may damage or destroy the natural resistance. It catalyzes the formation of highly reactive compounds, such as hydroxyl radicals, that cause damage to the macromolecular components of the cells, including DNA and proteins. ${ }^{3,4}$ Most environmental iron is in the $\mathrm{Fe}^{3+}$ state, which is almost insoluble at neutral $\mathrm{pH}$. To overcome the virtual insolubility and potential toxicity of iron, ingenious transport systems and related proteins have evolved, to mediate balanced and regulated acquisition, transport, and storage of iron in a soluble, biologically useful, non-toxic form. The various proteins involved in mammalian iron transport and metabolism are presented in Table I.

\section{The role of iron in normal cell growth}

Iron holds an important metabolic role on the regulation of the cell cycle. It activates the cyclin/cyclin-dependent kinase complexes, favouring the progression to the $S$ phase. Normally, all eukaryotic cells, entering the S-phase, upregulate transferrin receptor-1 expression, to obtain iron from the extracellular environment. Low levels of intracellular $\mathrm{Fe}^{3+}$ increase cyclin-dependent kinase inhibitor p21CIP1/WAF1 levels, delaying or inhibiting the transition to the S-phase. As a result, Bcl-2 is down-regulated and Bax levels are increased, conditions that activate caspase-3, caspase-8, and caspase-9, and lead to apoptotic cell 


\begin{tabular}{|c|c|}
\hline Protein & Function \\
\hline Duodenal Cytochrome B & Reduces $\mathrm{Fe}^{3+}$ to $\mathrm{Fe}^{2+}$ in the intestinal lumen, to facilitate iron absorbtion \\
\hline $\begin{array}{l}\text { Nramp1 (Natural resistance- } \\
\text { macrophage protein-1 }\end{array}$ & $\begin{array}{l}\text { Divalent iron transporter expressed in phagocytes. Participates in intracellu- associated } \\
\text { lar iron recycling. }\end{array}$ \\
\hline DMT1 (Nramp2 or DCT1) & $\begin{array}{l}\text { Associates and transports } \mathrm{Fe}^{2+} \text { from intestinal lumen - Intracellular iron transporter - } \\
\text { receives and delivers endosomal iron }\end{array}$ \\
\hline HFE protein & Binds to Tf Receptor - antagonizes Tf binding \\
\hline Ferroportin & Cell membrane iron transporter, both importer and exporter \\
\hline Hepcidin & Allosteric inhibitor of Fp - Induces Fp internalization and degradation \\
\hline Ceruloplasmin & Bivalent metal iron transporter mainly for copper and iron \\
\hline Hephaestin & Facilitates iron efflux by the enterocyte \\
\hline Hemojuvelin & GPI-linked membrane protein - Upregulates hepcidin gene expression \\
\hline Transferrin & Main iron transporter in the systemic circulation \\
\hline Transferrin Receptor-1 & Main cellular receptor for iron internalization \\
\hline Transferrin Receptor-2 & Mainly expressed in the liver - Binds only holotransferrin \\
\hline Matriptase-2 & Membrane-bound serine protease - Downregulates hepcidin gene expression \\
\hline Iron Regulatory Protein-1 & $\begin{array}{l}\text { Regulates intracellular iron homeostasis by binding to various iron regulatory elements - } \\
\text { Cytosolic aconitase activity }\end{array}$ \\
\hline Iron Regulatory Protein-2 & RNA-binding protein - Regulates translation of iron protein mRNA \\
\hline PCBP1 & Cytosolic chaperone - Trafficks iron from endosomes to cytosolic ferritin \\
\hline Lactoferrin & Tissue iron-binding protein with pleiotropic activity \\
\hline Ferritin & High molecular weight protein-complex - Main iron storage protein \\
\hline Mitoferrin & Inner mitochondrial membrane protein - Importer of iron to mitochondria \\
\hline Frataxin & $\begin{array}{l}\text { Mitochondrial iron-storage protein. Mediates iron transport to Iron-Sulfur cluster- } \\
\text { containing proteins and iron export from the mitochondrion }\end{array}$ \\
\hline ABCB7 & Main mitochondrial iron exporter \\
\hline Mitochondrial Ferritin & $\begin{array}{l}\text { High H-Ferritin molecule with higher affinity for iron than ferritin found in the } \\
\text { intramitochondrial space - Storage protein }\end{array}$ \\
\hline
\end{tabular}

Table 1. Proteins involved in iron transportation and metabolism.

death. ${ }^{5}$ Therefore, unavailability of extracellular iron, and consequently intracellular iron deprivation, results in impaired DNA synthesis, and the cell cycle progression is arrested at the transition from G1 to S phase. Studying gene expression profile alterations in the HL-60 cell line, it has been demonstrated that, under iron-deprived conditions 11 of 43 genes are $>50 \%$ inhibited. These genes are Rb, p21 WAF1/CIP1, bad, cdk2, cyclin-A, -D3, -E1, c-myc, egr-1, iNOS and FasL, all of which are essential for cell-cycle regulation and apoptosis. ${ }^{6}$ Apoptosis of the HL-60 cells, induced by iron deprivation, was not attributed to decreased bcl-2 or cmyc expression, but to the activation of the cyclin-dependent inhibitor p21WAF1/CIP1.5,7 However, although this metabolic step has long ago been recognized, it appears that additional key-points of cellular growth and development, exist, still vaguely known, which are controlled by intracellular iron and iron-containing proteins, since in some cases cell cycle arrest may also occur at the transition from the G2 to M phase. ${ }^{7}$

Iron is highly toxic for biologic substrates, due to its high oxidative potential and its ability to generate Reactive Oxygen Species (ROS) according to the Haber-Weiss reaction: $\left(\mathrm{O}_{2}^{-}+\right.$ $\left.\mathrm{H}_{2} \mathrm{O}_{2}=>\mathrm{HO}+\mathrm{O}_{2}+\mathrm{HO}^{-}\right) .{ }^{8}$ The major amount of intracellular iron is stored in ferritin, and the major cellular part of active iron implementation is the mitochondria. Iron is transported in the endomitochondrial space, with the assistance of the specific transporter mitoferrin and is stored in a specific type of ferritin, the mitochondrial ferritin. ${ }^{9}$ In the mitochondria, iron participates as coenzyme in the respiratory chains enzynes, the cytochromes, and in the formation of heme, which is incorporated in the other heme-containing proteins, 
hemoglobin and myoglobin. In the cytoplasm iron is usually found in the endosomes, loosely bound with transferrin, and ready to be transported to specific substrates, in various as yet poorly-defined proteins and molecules and is stored in ferritin. All the sources of nonferritin bound iron are collectively defined by the term intracellular labile iron.10,11,12

Iron is a major regulator of the cell cycle, by intervening with the formation and activity of the cyclin/cyclin-dependent kinase complexes. Depletion of intracellular iron by various iron chelators leads to cell cycle arrest, particularly in the G1 and the S phase, by producing an allosteric inhibition of cyclin-A, cyclin-E, and of cdc2 and cdk2. Moreover, it decreases intracellular levels of cyclin-D and cdk4 and changes retinoblastoma protein phosphorylation. ${ }^{13}$ In neuroepitheliomatous cells iron depletion reduces the expression particularly of the group D cyclins, and affects also negatively the expression of other cyclins. ${ }^{14}$ Iron chelators enhance the expression of several genes, involved in the downregulation of cell cycle progression, such as WAF1 and GADD45, in a p53-independent mechanism. ${ }^{15}$ In addition, cdc2 (p34) protein levels, which regulate the checkpoint of the G2/M phase transition, are decreased following incubation with iron chelators. ${ }^{16}$ A group from Sydney, Australia, specialized on iron metabolism has reported that iron depletion with deferroxamine (DFO) is associated with substantial decrease of cyclin D1 levels, through post-transcriptional modification of the protein, in a ubiquitin-independent manner, in contrast to what happens under normal conditions, in which cyclin D1 is cleared through proteasomal degradation. ${ }^{17}$ However, the expression of other cyclins, such as cyclin-E may be induced by iron deprivation, but since this cyclin form complex with cdk2, whose expression is down-regulated, the final result is again cell cycle arrest. ${ }^{16}$

Excluding cyclins and cdks, many other cytoplasmic biological pathways are severely modified in relation to the concentration of intracellular iron. One of this is the retinoblastoma gene protein $(\mathrm{pRb})$, which is a major regulator of the cell cycle. Under irondeplete conditions $\mathrm{pRp}$ is hypophosphorylated, an effect probably mediated by lactoferrin (Lf), and cell cycle is arrested. Lf is also a cell cycle regulator. In MCF-7 cells it induces Akt phosphorylation, which is followed by phosphorylation of $\mathrm{pRb}$ and of two G1-checkpoint Cdk inhibitors, p21Cip1/WAF1 and p27kip1.18 Hence the two inhibitors cannot cross nuclear membrane, remain in the cytoplasm and are degraded, whereas E2F transcription factor, the final inducer of the PI3K/Akt pathway, promotes the $S$ phase entry. Lf-induced higher cytoplasmic localization of p21Cip1/WAF1 levels are abolished when cells are treated with the PI3K inhibitor LY294002. Thus Lf behaves as an antagonist of the Cdk inhibitors. ${ }^{19}$

Other cell regulators, whose expression is influenced by the intracellular iron levels are p53 and Hypoxia-Inducing Factor-1a (HIF-1a). Iron is a cofactor of the enzyme HIF-1a prolyl hydroxylase, which down-regulates HIF-1a activity. Under iron-deprived conditions intracellular HIF-1a levels are increased, resulting in phosphorylation and stabilization of p53, whose levels are also increased. p53 in turn, induces transcription of the Cdk inhibitor p21Cip1/WAF1, with the previously mentioned consequences. ${ }^{20}$ Quercetin, a flavonoid antioxidant, strong metal chelator, increases and stabilizes HIF-1a levels in normoxia and inhibits cell proliferation, predominantly by decreasing the concentration of intracellular iron. ${ }^{21}$ An additional cell cycle control system, influenced by the intracellular iron levels is accomplished by the cytochromes. In cells without a functional mitochondrial respiratory chain, and also in normal cells, quenching of mitochondrial ROS synthesis with MitoQ, the proliferation rate is delayed. In both cases important cell-cycle regulators such as cyclin D3, 
cdk6, p18INK4C, p27KIP1 and p21 CIP1/WAF1are reduced. Therefore, functional loss of mitochondrial electron transport chain inhibits cell-cycle progression, and this may occur through the decreased concentration of ROS, leading to down-regulation of p21CIP1/WAF1.22

Finally iron appears to influence also the mRNA translational process. A Japanese group investigated the interaction of the multifactorial Y-box-binding protein (YB-1), with the ironregulatory protein-2 (IRP2) on translational regulation. Direct interaction of YB-1 and IRP2 is taking place in the presence of high iron concentration. YB-1 reduces the formation of the IRP2-mRNA complex, and both, YB-1 and IRP2 inhibit mRNA translation. However, coadministration of both proteins, abrogate the inhibitory effect of each protein alone. IRP2 binds to YB-1, in the presence of iron and a proteasome inhibitor. The interaction of these two proteins demonstrate the involvement of YB-1 and of an iron-related protein in the translational regulation. ${ }^{23}$ The various intracellular signal pathways in which there is a known implication of iron are depicted in Table 2.

\begin{tabular}{|lll|}
\hline \multicolumn{1}{|c}{ Activity } & Mediator & Result \\
Inactivation of p21CIP1/WAF1and p27kip1 & Uknown & Cell cycle progression, bcl-2 upregulation \\
Stabilization of cyclin D1 and -E & Uknown & Cell cycle progression, Bax downregulation \\
Stabilization of cdc2 (p34) & Uknown & G2 M phase progression \\
Activation of cyclin-A & Uknown & G1 S phase progression \\
P33/cdk2 complex formation & Uknown & G0 G1 phase progression \\
Phosphorylation of Rbp & Lactoferrin/Akt & Cell cycle progression \\
HIF-1a down-regulation & HIF-1a hydroxylase & Inactivation of p53 \\
Stabilization of mitochondrial & & \\
electron transport chain & Frataxin & ROS production, cell growth \\
TB-1/IRP2 complex formation & Uknown & mRNA translation enhancement \\
Ribonucleotide Reductase & Direct action & Deoxyribonucleotide formation \\
PI3K/Akt phosphorylation & Uknown & Cell cycle progression, differentiation \\
NFK-B nuclear maintenance/activation & Uknown & Transcriptional activation \\
Upregulation of IRF-1 gene expression & Uknown & Cytokines' gene expression \\
Upregulation of c-myc gene expression & Uknown & Cell proliferation \\
\hline
\end{tabular}

Table 2. Intracellular signal transduction pathways in which iron is implicated.

\section{The role of iron in immune function}

Since the majority of the effector functions of the immune system rely on the rapid development and fast proliferation of the immunocompetent cells, and taking into account the strong influence of cell growth, proliferation and differentiation by intracellular iron levels, it is self-evident that iron would exert significant regulatory role on the immune system. Moreover, since iron plays also a crucial role for the growth and development of many pathogens, a large variety of cellular mechanisms, dedicated to both, microbial growth and host defense, are orchestrated, upon a combat for iron acquisition or iron deprivation. ${ }^{24}$

The most primitive and less specific antimicrobial mechanisms of innate immunity are based on the development of proteins with high affinity to trivalent iron, such as transferrin (Tf) and Lf. These proteins are excreted by many cell types, but particularly by the neutrophils, to the extracellular space, bind iron from the circulating blood and tissues, thus 
creating an environment not favoring pathogens' growth. On the other hand, all pathogens elaborate specific iron-picking mechanisms from their environment, and in many instances also from the iron transporting proteins of the hosts, by synthesizing very high-affinity low molecular weight iron-chelators, the siderophores.

Lf, in addition to its iron-depriving properties, exerts various direct antimicrobial, antiviral, antifungal and antiparasitic activities. By directly interacting with the cellular surface, Lf inhibits microbial and viral adhesion, and consequently prevents the entrance to the host cells, probably by interfering to various glycosaminoglycan-type receptors and viral particles. It also acts at later phases, impairing viral DNA insertion and replication.25 Degradation of Lf by some proteolytic enzymes, leads to the formation of lactoferricin, which shares stronger antimicrobial activity and inhibits the growth of many pathogens, included multiresistant strains of bacteria and fungi. Both, Lf and lactoferricidin can prevent bacteremia, following food contamination of milk-fed animals with strong pathogenic bacteria or fungi (E.coli, Staph.aureus, C.albicans) and protect the intestinal mucosa from injury. ${ }^{26}$ Lf is also protective against the development of insult-induced Systemic Inflammatory Response Syndrome (SIRS) and its progression towards septic shock. This is accomplished through reduction or almost complete inhibition of the generation of intracellular and tissue oxidative stress, following LPS exposure, as measured by mitochondrial ROS expression, in a dose-dependent way. In vivo administration of Lf to experimental animals, significantly lowered LPS-induced mitochondrial dysfunction, estimated by decreased $\mathrm{H}_{2} \mathrm{O}_{2}$ release and mitochondrial DNA damage. ${ }^{27}$

More striking was the clarification of the ability of stress hormones and inotropes, to stimulate the growth of pathogenic bacteria. Using electron paramagnetic resonance spectroscopy and chemical iron-binding analyses it was demonstrated that catecholamines form direct complexes with $\mathrm{Fe}^{3+}$, found within $\mathrm{Tf}$ and Lf. The formation of such complexes results in the reduction of $\mathrm{Fe}^{3+}$ to $\mathrm{Fe}^{2+}$ and the loss of protein-complexed iron. Both forms of iron, released from Tf or Lf is thereafter used as bacterial nutrient sources. Therapeutically relevant concentrations of stress hormones and inotropes in human serum could directly affect iron binding by $\mathrm{Tf}$, so that the normally highly bacteriostatic tissue fluids may become significantly more supportive of the bacterial growth. The relevance of these catecholamine$\mathrm{Tf} / \mathrm{Lf}$ interactions to the infectious disease process is under ongoing research. ${ }^{28}$

Lf is also a very potent immunomodulator and anti-inflammatory protein. ${ }^{29}$ It recognizes specific microbial molecules/receptors, named Pathogen-Associated Molecular Patterns (PAMPs), which are LPS from the gram-negative cell wall, and bacterial unmethylated CpG DNA, acting either as a competitor for these receptors, or as a partner molecule, depending on the physiological status of the organism. By interacting with proteoglycans and membrane receptors of many cells of the innate- and adaptive immune system (lymphocytes, antigen-presenting cells, endothelial cells), Lf modulates the migration, maturation and function of these cells, and thus influences both arms of immunity. ${ }^{30}$ Bovine Lf attenuated Staphylococcal Enterotoxin B (SEB)-induced proliferation, IL-2 production and CD25 expression by transgenic mouse T-cells, an effect not induced through irondeprivation of staphylococci, but by lactoferricin. Cytokine secretion, following SEBstimulation by T-cell lines and by normal peripheral blood mononuclear cells, was also inhibited by Lf, suggesting a possible therapeutic applicability of this protein. ${ }^{31}$ When given orally, Lf is easily uptaken by enterocytes, but also by the CD3+ lymphocytes of the lamina 
propria and the small intestinal submucosal tissue, and is mainly distributed in the cytosol. However, occasionally, it may also be distributed in the nucleus, suggesting that it might exert a direct regulatory role. ${ }^{32}$

Similar immunoregulatory properties have been postulated for Tf, which plays an essential role for normal T-lymphocyte growth and early differentiation. The absolute number of Tcells has been found substantially reduced in hypotransferrinemic Trfhpx/hpx mice, and this could not be attributed to increased apoptosis. Moreover, the differentiation of CD4-CD8CD3-CD44-CD25+TN3 into CD4-CD8-CD3-CD44-CD25-TN4 cells was impaired, and a similar impairment of early $\mathrm{T}$-cell differentiation was observed in mice with reduced levels of Tf receptor. 33

The iron chelator DFO arrests cell cycle progression in activated T lymphocytes in the late G1 phase, before the G1/S border, by inhibiting transcription of the cdc2 gene, but has no effect on accumulation of cdk2, cdk4, or IL-2-transcripts. p34/cdc2 protein complex becomes undetectable, whereas synthesis of the $\mathrm{p} 33 / \mathrm{cdk} 2$ protein begins and is activated as an $\mathrm{H} 1$ histone kinase, but this complex is insufficient to complete the G1 phase. Synthesis and early accumulation of cyclin E and cyclin E-dependent kinase are not affected by DFO, but cyclin $\mathrm{A}$ and cyclin A-dependent kinase are inhibited, although cyclin-A mRNA levels remain normal. Thus, DFO blocks cell cycle progression, through inhibition of cyclin A appearance, which is a major component of the p33/cdk2 complex. ${ }^{34}$ DFO but not ferrioxamine (iron saturated DFO) inhibits growth and proliferation of the Jurkat T-cell line at the G0/G1 transition and induces apoptosis. However, iron-loaded Jurkat cells are not arrested. Silybin, a flavonoid antioxidant, free radical scavenger, acting also as iron chelator, shows a bimodal effect, inducing cell proliferation at low-, and DNA synthesis inhibition and apoptosis at high concentrations. The effect of silybin on the growth and viability of iron-loaded cells was similar to that of its iron complex, implying that the biological effects of silybin are different than those of DFO, and it probably shares pro-oxidant effect, via iron-catalyzed oxidation and generation of ROS. 35

The high frequency of infections, reported in hemodialysis patients, when receiving intravenous (IV) iron preparations, revealed that IV iron administration is associated with time-dependent increases of the intracellular oxidative stress in many immunocompetent cell populations, resulting in dysfunctional cellular immunity. The CD4+ lymphocytes are mainly affected, with a statistically significant reduction in their survival after incubation with all doses of iron preparations. IV iron products induce also various deleterious effects on CD16+ lymphocyte populations, which may also be mediated by intracellular ROS formation. ${ }^{36}$

Iron tetrakis (N-methyl-4'-pyridyl-porphyrinato: FeTMPyP) is a potent antiinflammatory and scavenger of ROS. Treatment of thymocytes with FeTMPyP results in the inhibition of various mitogen-or cytokine-induced proliferation signals, and of the DNA-binding activity of NF-kB and IL-2 secretion. Inhibitors of p38-MAPK and of the ERK protein block the growth and proliferation of ConA-stimulated thymocytes, the NF-kB activation and IL-2 secretion. ${ }^{37}$ Interferon regulatory factor-1 (IRF1) regulates the expression of genes involved in the inflammatory response and cell cycle control. IRF1 expression is transcriptionally mediated by TNF- $\alpha$ or IFN- $\gamma$, via iron-dependent pathways and is inhibited when cells are pretreated with iron chelators. Addition of exogenous iron reconstitutes cytokine responsiveness, indicating that iron is the target for the chelator effect. ${ }^{38}$ 
In addition to Lf, ferroportin (Fp), an iron efflux protein, strongly influences host response to infection. Murine macrophages overexpressing $\mathrm{Fp}$ show impaired intracellular M.tuberculosis killing at early stages of infection. When challenged with LPS or M.tuberculosis infection, control macrophages increase NO synthesis, but macrophages overexpressing Fp had significantly reduced NO and iNOS mRNA and protein production, thus limiting the bactericidal activity of these macrophages. IFN- $\gamma$ reversed the inhibitory effect of Fp on NO production, findings suggesting a role for $\mathrm{Fp}$ in attenuating macrophage-mediated immune response. ${ }^{39}$ Hepcidin, the allosteric inhibitor of $\mathrm{Fp}$, regulates intracellular iron levels by interacting with, and promoting Fp degradation. All immunoregulatory cells express hepcidin mRNA; hepcidin mRNA expression increases after T-lymphocyte activation and in response to holotransferrin (Fe-Tf) or ferric citrate challenge. Therefore, low hepcidin expression impairs normal lymphocyte proliferation. ${ }^{40}$

Normal tissue macrophages are polarized, through the action of cytokines, into classically(M1) and alternatively-activated (M2). M1 macrophages have low IRP-1 and -2 binding activity, express high levels of $\mathrm{H}$-ferritin, low levels of Tf receptor- 1 and internalize iron, only at high extracellular concentrations. Conversely, M2 macrophages have high IRP-binding activity, larger intracellular labile iron pool, express low levels of $\mathrm{H}$-ferritin and high levels of Tf receptor-1, and effectively internalize and release iron, even at low concentrations. Iron export correlates with Fp expression, which is higher in M2 macrophages. In the absence of iron, only M1 macrophages are effectively activating antigen-specific, MHC class II-restricted $\mathrm{T}$ cells. Thus finally, cytokines control iron handling, by differentiating macrophages into a subset with relatively-low intracellular iron content (M1), or a relatively-high iron containing subset, endowed with the ability to recycle iron (M2). ${ }^{41}$ Besides the classical mechanisms of antimicrobial activity (peptidic antibiotics, induction of oxidative stress, leading to respiratory burst) macrophages can deprive intracellular pathogens of necessary nutrients, and most importantly of iron. Moreover, according to the type of phagocytized pathogen, they can modulate, even the extracellular environment, impeding pathogens the access to essential nutrients. Thus various membrane transporters may remove nutrients from vacuolar compartments, degrade growth factors, and sequester other molecules, important for microbial growth, in a way similar to iron deprivation. ${ }^{42}$

Iron deficiency has been associated with various immune abnormalities, and particularly with impaired lymphocyte proliferation. T-cells from iron deficient mice exhibit poorer monocyte stimulatory activity following Con-A activation, as estimated by CD80 and CD86 expression on antigen presenting cells. The addition of DFO increased the expression of both markers on resting $\mathrm{B}$ and $\mathrm{T}$ cells. Lymphocyte proliferative responses to mitogens correlated positively with CD80 and CD86 expression, but negatively with the percentage of CD80+ cells. Therefore, the impaired lymphocyte proliferation of iron deficiency cannot be attributed to reduced CD80 and CD86 expression. ${ }^{43}$

The immunoregulatory properties of ferritin include binding to T lymphocytes, suppression of the delayed-type hypersensitivity and of antibody production by B lymphocytes, and impairment of phagocytosis by the granulocytes.

\section{The role of iron in inflammatory and neoplastic diseases}

Iron plays a major role in the generation and perpetuation of inflammatory processes. Many chronic inflammatory diseases are directly influenced by the intracellular and extracellular 
iron concentrations. Disease activity, and particularly the manifestation of serositris and various hematological disturbances in rheumatoid arthritis, systemic lupus erythematosous, Still's disease, dermatomyositis, and other collagen diseases are strongly correlated with serum and tissue ferritin levels. ${ }^{44,45}$ Ferritin and iron homeostasis are implicated in the pathogenesis of many other disorders, including atherosclerosis, Parkinson's disease, Alzheimer disease, and restless leg syndrome. Iron contributes to the synthesis of myelin, and severely iron deficient patients exhibit impaired myelin formation. In patients with multiple sclerosis, serum and cerebrospinal fluid levels of Tf and ferritin levels have been found significantly elevated only during progressive active disease. ${ }^{46}$ Brain tissue of patients with multiple sclerosis exhibits abnormal distribution of Tf and ferritin. ${ }^{47}$ Ferritin binding to the inflammatory lesion and the immediate periplaque region within the white matter is practically absent, but returns to normal as the distance from the lesion increases. Therefore, the loss of ferritin binding is correlated with demyelination, accompanying multiple sclerosis.48 Reactive Oxygen Species participate in the pathogenesis of allergic encephalomyelitis, whereas the infusion of apoferritin in experimental animals may induce a remission status. ${ }^{49}$ Thyroid hormone upregulates ferritin genes' expression, and elevated serum ferritin levels have been reported in patients with subacute thyroiditis, which were correlated with disease activity. These levels were higher, as compared to patients with Graves' disease and Hashimoto's thyroiditis. ${ }^{50}$

Ferritin synthesis is regulated by the main proinflammatory cytokines (TNF-a, and IL-1a) at various levels (transcriptional, post-transcriptional, translational) during cellular development, differentiation and inflammation. Cytokine-induced cellular response to infection by various pathogens includes the upregulation of ferritin genes. Translation of ferritin is induced by IL-1 $\beta$, IL-6 and TNFa, and iron is required for this regulation. Ferritin is accumulated in macrophages during various inflammatory conditions, when serum iron levels are decreased, leading to the formation of ferritin molecules with high content of iron. 51

High heme oxygenase-1 (HO-1) expression, elevated ferritin accumulation in renal tubules and increased iron deposition in renal proximal tubules have been reported in patients with immunohemolytic anemia. ${ }^{22} \mathrm{HO}-1$ degrades heme to biliverdin, carbon monoxide and free iron. HO-1 expression is induced among others, by proinflammatory cytokines and high intracellular ROS levels. This enzyme appears to have significant immunoregulatory properties, acting as inhibitor of immune reactions and participating in the pathogenesis of many inflammatory, infectious, allergic and autoimmune diseases and conditions, and has been proposed as a possible target inducing immunosuppression in allogeneic stem cell transplantation. 53

Besides the stimulatory role on DNA synthesis, iron interferes with cell proliferation, by enhancing c-myc expression. Regulation of c-myc expression is crucial for the maintenance of cellular homeostasis. Overexpression or abnormal intracellular localization of c-myc results in the activation and deregulation of this oncogene. Surprisingly, when added to Burkitt's lymphoma cell lines, iron markedly inhibits cell proliferation, through cell cycle arrest in the G2/M transition, followed by a significant decrease in c-myc expression. A similar effect is not observed in cell lines with constitutive c-myc expression. Downregulation of c-myc, which is independent from cell cycle blockade, leads to apoptotic cell death, implying the existence of another iron-dependent cell cycle regulatory mechanism, involving modulation of c-myc expression. ${ }^{54}$ 
Antisense oligodeoxynucleotide treatment against $\mathrm{H}$ - and L-ferritin chains increased the steady-state labile iron pool and the production of ROS after oxidative challenges and down-regulated Tf receptors, whereas it had no effect on the long-term growth of the cells. However, repression of ferritin synthesis facilitated renewal of the growth and proliferation of cells pre-arrested at the G1/S phase. Renewed cell growth was significantly less dependent on external iron supply, when ferritin synthesis was repressed, and its degradation was inhibited by lysosomal antiproteases. ${ }^{55}$

\section{Iron and bacterial infections}

Bacteria are confronted with a low availability of iron owing to its insolubility of the $\mathrm{Fe}^{3+}$ form, or its binding to host proteins. Free iron concentration in the host environment is about, or lower than $10^{-15} \mathrm{M}$ and in some instances as low as $10^{-24}$. Bacteria and other microorganisms need powerful and sophisticated mechanisms to acquire iron. Iron availability is a signal, alerting pathogenic bacteria, when they enter the hostile environment. When bacterial pathogens infect a host, cytotoxins damage the host cells releasing ferritin, hemolytic toxins lyse erythrocytes releasing hemoglobin, and Lf is produced by neutrophils and epithelial cells. The bacteria cope with the iron deficiency, by developing various uptaking systems: siderophores (low-molecular weight substances, with very high affinity for iron), systems for free heme and heme bound to hemoproteins (hemoglobin, hemoglobin-haptoglobin, heme-albumin, heme-hemopexin) and siderophorebased mechanisms to acquire iron from the iron-binding proteins Tf and Lf.

Pathogens encounter a period of iron starvation, upon entering their host and they sense alterations of the iron status, via the Ferric Uptake Regulator (FUR). The FUR protein plays a key role in the transcriptional response to iron of Escherichia coli and other gram-negative bacteria. The mechanism of action of FUR is repression of siderophore production and iron transport promoters. When iron is limiting, FUR protein is inactive as a repressor. This results in derepressed transcription of genes, involved in siderophore synthesis, and highaffinity iron uptake. FUR homologues are present in many bacteria. ${ }^{56}$ In addition hemesensing systems have been evolved by many pathogens, like Staphylococcus aureus, Bacillus anthracis, and Corynebacterium diphtheriae. For instance, $S$. aureus is able to sense heme through the heme sensing system (HssRS), two-component system that detect the presence of toxic levels of exogenous heme. Upon sensing heme, HssRS directly regulates the expression of the heme-regulated $\mathrm{ABC}$ transporter HrtAB, which alleviates heme toxicity. ${ }^{57}$ In some halophilic bacteria, such as Chromohalobacter salexigens, iron homeostasis is coupled to the reaction to osmotic stress, through the activity of FUR. A decrease in iron and histidine requirements and a lower level of siderophore synthesis were observed at high salinity. 58

Siderophores (named after the Greek word for iron carriers) are low molecular weight ironbinding complexes, produced and secreted by bacteria, fungi and plants. These molecules target ferric iron $\left(\mathrm{Fe}^{3+}\right)$, the form of iron found in well oxygenated environment in the host. Based on the metal chelating group, there are three major classes of microbial siderophores, the catecholate, the hydroxycarboxylate and the hydroxamate class. These substances exhibit extremely high affinity for iron, and hold it with three bidentate bonds. The high affinity is specific for iron, and does not extend to other bivalent cations. Siderophore production is enhanced in conditions of iron starvation, and many metabolic steps of their 
biosynthesis have been characterized. Siderophores have higher binding constants for iron, than do Tf and Lf, and thus are capable of detaching iron from these proteins. Their biosynthesis is confined to bacterial and fungal cells, and their expression increases the virulence of these species. ${ }^{59}$ The most commonly encountered siderophores are described in Table 3.

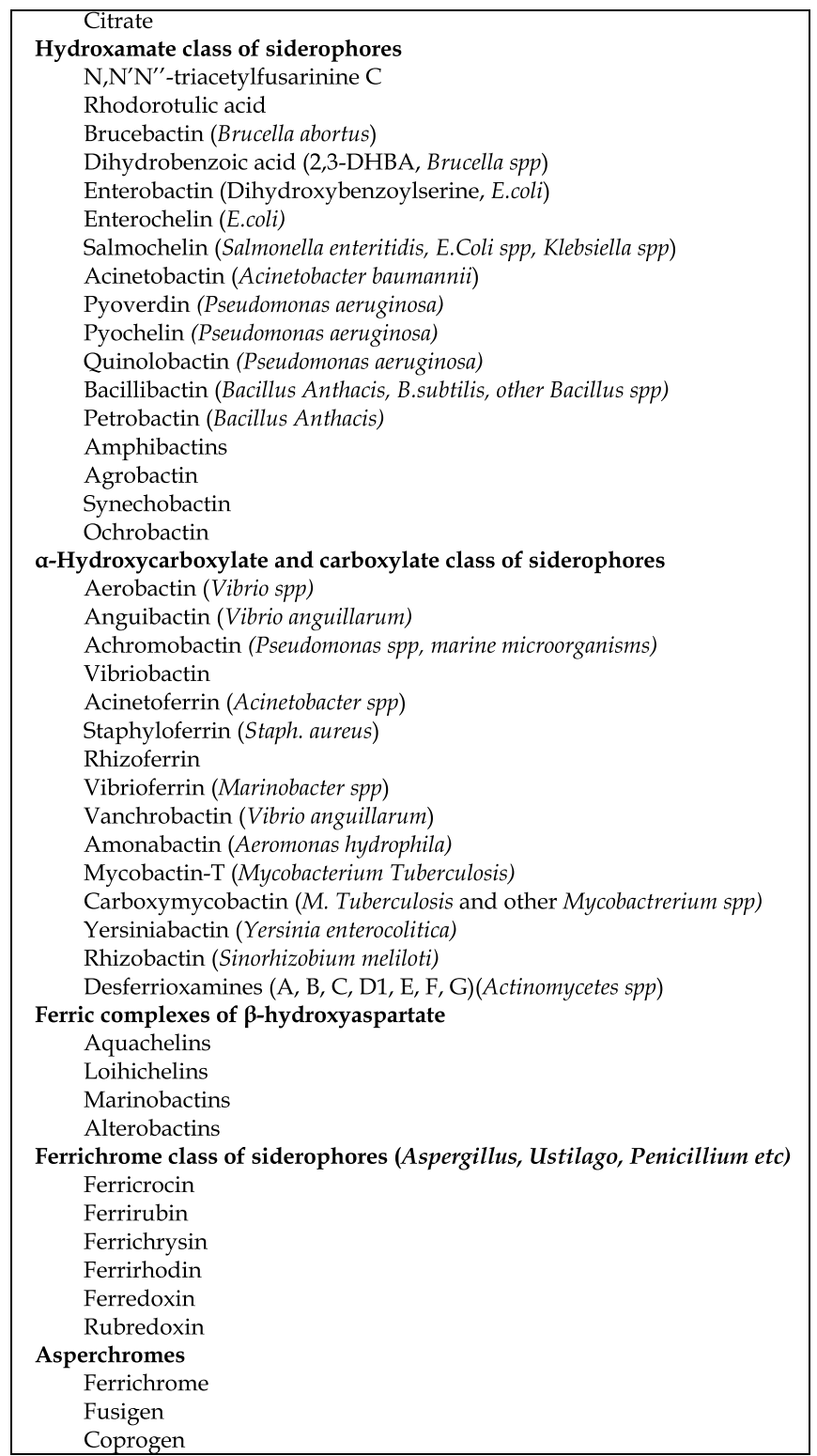

Table 3. The major microbial sideropophores. 
Iron loaded siderophores bind to cognate receptors, expressed at the bacterial surface. In gram negative bacteria, there is an outer membrane, external to a very thin (1-nm) peptidoglycan layer. Peptidoglycan is the structure that confers cell wall rigidity and resistance to osmotic lysis, in both, gram positive- and gram negative bacteria. In gram positive bacteria peptidoglycan is the only layered structure external to the cell membrane and is thick $(20-80 \mathrm{~nm})$. In gram negative bacteria the ferric-siderophores use outer membrane transporters, because they are large enough to pass through the porins (the small pores in the bacterial outer membrane that allow passive diffusion of molecules with molecular weight $<600 \mathrm{Da}) .{ }^{60}$ The energy for the transport of these ligands across the outer membrane is delivered from the inner membrane, by a complex of three cytoplasmic membrane proteins TonB, ExbB, and ExbD.61,62 TonB spans the periplasm, contacts outer membrane transporters by its C-terminal domain, and transduces energy from the proton motive force to the transporters. There is no need for TonB-ExbB-ExbD complex and outer membrane trasporters in gram-positive bacteria, as there is no outer membrane. Each class of siderophore is shuttled by a specific periplasmic binding protein (PBP) to the inner membrane. For example, FhuD is a siderophore binding PBP with a well-determined structure, found in gram negative and gram positive bacteria. ${ }^{63}$ When iron-replete siderophores arrive at the microbial cytoplasmic membrane, they are taken up across the membrane by periplasmic binding protein-dependent $A B C$ transporters in an ATPdependent process. ABC trasporters comprise of two transmembrane domains forming a channel for the siderophore, to pass through and two nucleotide binding domains that hydrolyse ATP. The complex is internalised into the bacterium and the iron is released by proteolysis or by the action of enzymes that reduce $\mathrm{Fe}^{3+}$. $\mathrm{Fe}^{2+}$ is incorporated into metalloenzymes or stored in bacterioferritin or in the related Dps proteins. The genes for siderophore biosynthesis and transport are usually under transcriptional control in response to the cellular pool of iron.

At the site of infection, leukocytes secrete siderocalin (also called lipocalin-2, neutrophil gelatinase-associated lipocalin). Siderocalin is also produced by epithelial cells and macrophages. Upon encountering invading bacteria, the Toll-like receptors on immune cells stimulate the transcription, translation and secretion of siderocalin. Secreted siderocalin then binds to ferric-siderophore complexes, participating in the antibacterial iron depletion strategy of the innate immune system. $64,65,66$ However, pathogens produce structurally modified enterobactin-type siderophores, that are resistant to siderocalin and are known as stealth siderophores. ${ }^{67}$ The first glucosylated siderophore described was salmochelin, a Cglucosylated enterobactin produced by Salmonella species, uropathogenic Escherichia coli strains, and some Klebsiella strains. ${ }^{68}$

Except of siderophores, gram positive and gram negative bacteria may use free heme or heme bound to host hemoproteins as iron source. ${ }^{69,70}$ Like siderophores, this iron uptake pathway includes a TonB-dependent outer membrane receptor, while the transport across the cytoplasmic membrane requires periplasmic and inner membrane proteins comprising the ABC systems, which utilize the energy derived from ATP hydrolysis. ${ }^{71}$ In addition, bacteria elaborate hemophores which are molecules that can remove heme from host hemoproteins. Bacterial hemophores are secreted to the extracellular medium, where they scavenge heme from various hemoproteins, due to their higher affinity for this compound, and return it to their specific outer membrane receptor. ${ }^{72}$ An example is Serratia marcescens, that secretes a heme-binding protein, HasA, which functions as a hemophore that catches 
heme and shuttles it to a cell surface specific outer membrane receptor, HasR. The HasR receptor belongs to the TonB-dependent family of outer membrane receptors. HasAp, a gene from Pseudomonas aeruginosa has been isolated. HasAp is an iron-regulated extracellular heme-binding protein that shares about 50\% identity with HasA and is required for $P$. aeruginosa utilization of hemoglobin iron. ${ }^{73}$

Pathways analogous to those described above are also utilized in gram-negative bacteria, for the uptake of iron from the iron-binding proteins Tf and Lf. Lf and Tf receptors are present in pathogenic bacteria. ${ }^{74}$ Iron must be stripped away from Lf and ferritin prior to be transported into the bacterial cell. Two proteins, Tf-binding protein A (TbpA) and Tfbinding protein $\mathrm{B}(\mathrm{TbpB})$, function like the Tf receptor in many pathogenic bacteria, such as Neisseria meningitides. The expression of these genes is induced along with several other proteins under iron-restricted conditions. ${ }^{70}$ Lf-binding protein A (LbpA) and Lf-binding protein $\mathrm{B}(\mathrm{LbpB})$ have been identified as outer membrane receptors for Lf. The extracted iron is then transfered into the periplasm. Within the periplasm, the ferric ion is complexed by ferric ion-binding protein $\mathrm{A}(\mathrm{FbpA})$. FbpA shuttles the iron to an inner membrane complex consisting of two proteins, the inner transmembrane $\mathrm{FbpB}$ and the cytoplasmic ATPase FbpC, finally transported into the cytoplasm.

Pseudomonas aeruginosa produces 2 siderophores under iron-limiting conditions, pyoverdine and pyochelin. Vanadium a rare metal, and probably other metallic ions, form complexes with both of these siderophores and strongly inhibit P.aeruginosa growth. Pyoverdindeficient mice were more sensitive to vanadium, whereas pyochelin-negative mutants were more resistant. V-pyochelin strongly inhibits pseudomonas growth, increasing the activity of Superoxide Dismutase by about two times. Therefore, it appears that V-pyochelin catalyses a Fenton-type reaction, in which superoxide anion $\mathrm{O}^{2-}$ is generated, and vanadium compromises pyoverdin utilization. ${ }^{75}$ However, in some pyoverdin deficient strains another siderophore molecule was identified, and this is quinolobactin. Its receptor is the $75-\mathrm{kDa}$ iron-repressed outer membrane protein (IROMP) and the quinolobactin-mediated iron uptake system functions only in the absence of pyoverdine, and is repressed by pyoverdine. ${ }^{76}$ Multicopper ferroxidases are enzymes that oxidize $\mathrm{Fe}^{2+}$ to $\mathrm{Fe}^{3+}$ in the microbial environment, so that iron will be transformed in a less active form, easily uptakable by microbial siderophores. Ps. aeruginosa possesses such an enzyme. Mutant strains are unable to grow with $\mathrm{Fe}^{2+}$ as iron source, because they cannot uptake iron. Thus multicopper ferroxidase represents another iron acquisition mechanism, important for virulence and pathogenicity of many bacteria. ${ }^{77}$

Some strains of Vibrio anguillarum produce a catechol-type siderophore named vanchrobactin, whose biosynthesis is under complex regulation, in an effort to adjust its production according to environmental iron concentrations. ${ }^{78}$

Although iron is important for all the scale of microorganisms, some types are less strictly dependent on iron than others. Moreover, growth characteristics and virulence of intracellular pathogens may vary, according to the type of infected cells. Chlamydia pneumoniae is an intracellular bacterium, causing chronic inflammatory disease in humans. When endothelial cells and monocytes were infected with C.pneumoniae, supplemented with iron and then stimulated with IFN- $\gamma$, iron had no significant effect on Chlamydia growth within monocytes, whereas on endothelial cells iron enhanced its proliferation and differentiation, and IFN- $\gamma$ had an inhibitory effect. C.pneumoniae infection induced a pro- 
inflammatory immune response in monocytes, but not in endothelial cells and Chlamydia remains in a persistent-latent form within monocytes but it differentiates and proliferates within endothelial cells. ${ }^{79}$

Various drugs may interfere with the microbial-host battle for iron acquisition. The calcium channel blocker nifedipine enhances host resistance against intracellular pathogens, by restricting iron availability. In a murine macrophage cell line, nifedipine significantly reduced intracellular bacterial survival of Salmonella Typhimurium and Chlamydophila pneumoniae. Moreover, in mouse models of iron overload, nifedipine was capable of mobilizing tissue iron. When these mice were infected intraperitoneally with Salmonella, and subsequently treated with nifedipine for 3 consecutive days, bacterial counts in livers and spleens were significantly reduced and survival was prolonged, compared with placebotreated animals. Nifedipine increased Fp expression in the spleen, whereas splenic levels of ferritin and serum iron concentrations were reduced. Therefore, nifedipine, and probably other drugs, may induce Fp expression, export iron from macrophages and thus restrict iron availability for intracellular pathogens. 80

The Brucella spp are facultative intracellular pathogens. The two predominant host cell types inhabited by Brucella are macrophages and placental trophoblasts. These bacteria produce 2,3-dihydroxybenzoic acid (2,3-DHBA) in response to iron limitation in vitro, which functions as a siderophore. ${ }^{81}$ In addition, Brucella abortus strain 2308 produces brucebactin, a more complex 2,3-DHBA-based siderophore.82 It has been showed that these siderophores are not required for wild-type replication of $B$. abortus in cultured murine macrophages. Paulley et al showed that heme is an important iron source for the bacterium, during chronic infection. Heme has a key role during the stationary phase, allowing Brucella to maintain intracellular residence in host macrophages. Recent analysis of the known Brucella genome sequences revealed a homolog of the heme transporter shuA gene of Shigella dysenteriae and has been given the designation bhuA (Brucella heme utilization). ${ }^{83,84}$ The gene encodes a TonB-dependent outer membrane heme transporter. In Brucella spp the genes involved in the transport of heme across the cytoplasmic membrane are located in an operon distant from the $b h u A$ locus. 85 In other gram negative bacteria, the genes for the periplasmic binding protein-dependent $A B C$ transporter, responsible for the transportation of heme across the cytoplasmic membrane, are located in an operon with the gene for the TonBdependent outer membrane transporter.

\section{Iron and mycobacterial infections}

Mycobacterium tuberculosis (Mtb) has developed various means of attacking the host system. One such crucial strategy is the exploitation of the iron resources of the host system. When Mtb evade the mammalian immune system, it resides within macrophages in an early phagosome, whose maturation to the late phagosome and phagolysosome stages is blocked. The control of the intraphagosomal environment is crucial. Macrophages digest senescent erythrocytes and degrade heme, thus accumulating iron. Iron mainly egresses the macrophage bound to Tf, although a part of it is incorporated into ferritin in the cytosol. Other main iron sources for the macrophage are the hemoglobin-haptogobin complex, taken up via the hemoglobin scavenger receptor CD163 during hemolysis, and iron bound to Tf and Lf that enters macrophages, via the transferrin-transferrin receptor and lactoferrin receptor pathway, respectively. ${ }^{71}$ Iron is exported from the cell via Fp-1 which is the 
receptor for hepcidin. In the presence of inflammation serum hepcidin is high and the binding to $\mathrm{Fp}$ induces conformational changes to this molecule, resulting in allosteric inhibition of its function, thus halting iron egress, and promoting internalization and degradation of Fp. ${ }^{86,87}$

Within its phagosome, Mtb acquires iron from the cytoplasmic sources or from the Tf/Tfreceptor complex. ${ }^{88}$ By the time Mtb faces the low-iron environment of the phagosome, several Mtb genes, involved in the biosynthesis of siderophores, are induced. There is a dual mycobacterial siderophore system, made of mycobactins, the water-soluble carboxymycobactin, and the lipophilic mycobactin- $T$, which transfers iron captured by the hydrophilic carboxymycobactin, across the cell wall. 89 Mycobactin, except from participating in iron internalization, it prevents sudden influx of excess iron, when the metal becomes available. For the transportation across the cell membrane, a reductase converts $\mathrm{Fe}^{3+}$ mycobactin to the $\mathrm{Fe}^{2+}$ form. The ferrous ion, possibly complexed with salicylic acid, is then shuttled across the membrane, either for direct incorporation into various porphyrins and apoproteins, or for storage of iron within the bacterial cytoplasm. The overall process of iron acquisition and utilization requires the activation of a number of mycobacterial genes. $\mathrm{Mtb}$ contains four potential iron-dependent regulators, belonging to two different families of metalloregulatory proteins. Two genes, fur $A$ and $f u r B$, encode proteins, belonging to the FUR family. The other two genes, IdeR and SirR are members of the DtxR (diphtheria toxin repressor) family. IdeR is an essential regulator with a major role in controlling iron metabolism, by repressing siderophore production, activating iron storage genes and positively regulating oxidative stress responses. ${ }^{90}$ In Mtb-infected macrophages an upregulation of IdeR was found as part of the bacterial protective mechanism against ironmediated oxidative stress.

Immune cell derived mediators control systemic and cellular iron homeostasis. On the other hand, iron affects the activity of transcription factors related to immune responses, and therefore, the secretion of cytokines. ${ }^{91}$ Iron, directly inhibits the action of IFN- $\gamma$, which is crucial for the control of intracellular infections. In iron-loaded macrophages, an inhibition of IFN- $\gamma$ mediated pathways is noted while intraphagosomal Mtb growth is stimulated.92 However, IFN- $\gamma$ activation of human monocytes decreases iron availability to Mtb. ${ }^{93}$ Sow et al. examined the expression of hepcidin in macrophages, infected with Mycobacterium avium and Mtb and found that IFN-Y induced high levels of hepcidin mRNA and protein by pathways involving STAT1 activation and Toll-like receptors TLR2 and TLR4. ${ }^{94,95}$

Dietary iron overload, mainly in rural populations in sub-Saharan Africa, causing iron overload of macrophages and hepatocytes may increase the risk of tuberculosis. The incidence of tuberculosis has markedly increased the last decades, primarily as a result of the infection with the human immunodeficiency virus (HIV). Acquired immunodeficiency syndrome (AIDS) patients exhibit alterations in iron metabolism that lead to increased deposition of this element in the tissues. Such alterations may underlie the increased susceptibility of AIDS patients to mycobacterial infections. Many ongoing studies are aiming to investigate the Mycobacterial iron-acquisition pathways and their role in the treatment of tuberculosis e.g. synthesizing selective inhibitors of iron metabolism that may be helpful as chemotherapeutic agents. Table 4 resumes the most commonly encounterd iron uptaking mechanisms, during bacterial growth. 
- Expression of receptors for iron containing proteins of the host (Transferrin, Lactoferrin, Hemoglobin)
- Adaptation of the expression of a polymorphic Tf receptor according to host's Tf structure
- Non-enzymatic reduction of $\mathrm{Fe}^{2+}$ to $\mathrm{Fe}^{3+}$ by 3-hydroxylanthranilic acid or melanin (C.neoformans)
- Enzymatic oxidation of the $\mathrm{Fe}^{2+}$ to $\mathrm{Fe}^{3+}$ out of bacteria in the surroundings (various ferroxidases)
- Production and release of iron-depleted siderophores and uptake of iron-saturated siderophores
- Expression of specific siderophore ligands in the outer surface of the bacterial membrane
- Oxidation of heme by heme oxygenase and uptaking of the iron from the porphyrin ring
- Production and release of hemophores (removing heme from hemoproteins, for example HasA)
- Expression of specific hemophore ligands in the outer surface of the bacterial membrane (HasR)
- Elaboration of iron permease-ferroxidase complex (Ftr1-Fet3, Aft1-Aft2, CIR1, HapX/Php4)
- Production, release and uptake of specific protein iron transporters (Sit1 in C. Glabrata)
- Induction of iron-starving conditions in the host and upregulation of Tf receptor (Intracellular pathogens)
- Modulation of the IRPs and/or the IRE of critical genes of the host cells (Intracellular pathogens)

Table 4. Summary of the most common iron upatking mechanisms elaborated by pathogens.

\section{Iron and fungal infections}

The larger proportion of systemic fungal infections are opportunistic i.e. an important factor for their occurrence is a background of primary or secondary (in the majority of cases iatrogenic) immunosuppression. For all fungal pathogens iron is essential for many metabolic processes and the most intelligent and complex systems of iron acquisition from the host cells and tissues, is found among various fungal strains. Particularly for fungi, iron is a major virulence factor. ${ }^{96}$ Many if not all, host-developed mechanisms of host defence against pathogenic fungi are orchestrated through iron deprivation. Lf, produced and released mainly by neutrophils and monocytes, represents the major fungistatic factor of human serum, milk and other fluids. ${ }^{97}$

Fungal pathogens require $10^{-7}$ to $10^{-6} \mathrm{M}$ iron for their growth, and, therefore, serum and other biological fluids and tissues, containing $<10^{-15}$ and as low as $10^{-24} \mathrm{M}$ of iron are normally fungistatic for all species, including Candida, Aspergillus and Zygomycetes. ${ }^{98}$ The fungistatic properties of human serum are completely abolished by the in vitro addition of exogenous iron, and Candida albicans can grow in serum cultures with Tf saturation $>90 \%$, but not in serum with normal Tf saturation. Diseases and conditions, accompanied by a high iron burden have been associated with increased susceptibility to fungal infections. Among these are tissue hypoxia, diabetic ketoacidosis, acidosis of any other cause, tissue damage and necrosis, post-traumatic states or those induced by chemotherapy, hemochromatosis, liver disease and cancer. Patients with acute myelogenous leukemia or other hematologic malignancies have commonly an excess of iron, and particularly, non-transferrin-bound iron, which is further increased following chemotherapy,99 either because of tissue damage or, in some cases, as a result of circulating iron complexes. Such complexes are produced by the leukemic cells and are liberated following their death, induced by chemotherapy. All the above, render leukemic neutropenic patients particularly vulnerable to fungal infections. Liver iron overload, in patients undergoing orthotopic liver transplantation, is also a 
predisposing factor for the development of invasive fungal infections, and such infections occur almost three times more commonly among transplanted patients with elevated levels of iron in the liver. 100

Iron uptake by fungi is accomplished by specific transport systems, in which an initially $\mathrm{Fe}^{3+}$ form is reduced to $\mathrm{Fe}^{2+}$ iron, through the action of specific cell surface reductases (ferroxidases). Ferrous iron is then internalized by three different mechanisms. The first is achieved thank to the high affinity of the iron-containing ferroxidases for a specific type of fungal transport proteins, named permeases. The iron permease-ferroxidase complexes (Ftr1-Fet3) easily transverse the fungal wall and cell membrane, and iron is thereafter provided intracellularly. There are three types of specific transcriptional activators or repressors of the genes encoding ferroxidases and permeases, which modulate their expression under iron-deprived conditions: the Aft1 and Aft2 activators in Saccharomyces cerevisiae and other yeast, or the Cryptococcus iron regulator gene (CIR1) in Cryptococcus neoformans, the GATA-type repressors, such as Sfu-1, present in many fungal species and the HapX/Php4 in Schizosaccharomyces pombe and Aspergillus species. A second mechanism or iron acquisition involves the production of siderophores, which are excreted through the fungal wall in the deferric form, bind iron, and then are taken up by the fungi. Finally, a third mechanism is related to a fungal heme oxygenase, which takes up iron from heme. ${ }^{101,102}$

C. albicans possesses two high-affinity iron permease genes that are essential for its virulence. Iron permeases are encoded by iron-responsive genes, which are regulated by the specific transcriptional activator Hap43 and the repressor Sfu1. Deletion of these genes renders mutant strains non-virulent. ${ }^{103}$ Various iron overload conditions enhance C. albicans growth and increase the mortality rate of infected mice. Elevated serum iron levels have been documented among patients with urogenital candidiasis. In C. albicans CIR1 is a gene regulating iron homeostasis, as well as calcium and cAMP signaling, cell wall integrity, and the expression of all virulence functions, including capsule and melanin formation and growth at host temperature. Hap43 protein is essential for the growth and virulence of C.albicans under low-iron conditions, and is accumulating in the nucleus. Hap43 is not required for iron acquisition, but it is responsible for repression of genes encoding irondependent proteins involved in mitochondrial respiration and iron-sulfur cluster formation. There is an association between Hap43 and the global corepressor Tup1 in response to iron deprivation. ${ }^{104}$

Sit1 is a combined siderophore-iron transporter, found in C. glabrata. For this yeast iron acquisition is necessary, not only for the growth and virulence, but also for maintaining its survival against the fungicidal activities of macrophages. Within the Sit1 transporter, a conserved extracellular SIderophore Transporter Domain (SITD) has been identified, that is critical for the ability of C. glabrata to resist macrophage killing. C. glabrata senses altered iron levels within the phagosomal compartment and Sit1 functions as a determinant of survival in a way that is dependent on the iron status inside the macrophage. ${ }^{105}$

Non-enzymatic reduction of ferric iron by 3-hydroxylanthranilic acid and melanin has been documented in Cryptococcus neoformans. 106 The expression of permease genes in Aspergillus and zygomycetes is upregulated during their growth and virulence. ${ }^{107}$ The growth, survival and virulence of Aspergillus fumigatus and other mold species in serum is associated with the removal of iron from Tf and other iron-containing proteins. ${ }^{108}$ This is accomplished by 
siderophores. HapX, a bZIP-type transcriptional regulator, is a very important gene, which sets up the adaptation mechanism to iron starvation in A. fumigatus. HapX represses all irondependent and mitochondrial-orchestrated metabolic activities, including respiration, TCA cycle, amino acid metabolism, iron-sulfur cluster formation and heme biosynthesis. Iron starvation induces significant modulation of the amino acid pool and HapX coordinates the production of siderophores and their precursor amino acid ornithine. HapX activity is restricted to iron-deplete conditions, therefore, HapX-deficiency causes significant attenuation of virulence in a murine model of aspergillosis. ${ }^{109}$

Fungal species are capable of synthesizing many different siderophores; however, the most important and most commonly found in Aspergillus and zygomycetes are $\mathrm{N}^{\prime \prime}, \mathrm{N}^{\prime}, \mathrm{N}$ triacetylfusarinine $\mathrm{C}$ and ferricrocin. Aspergillus uses two iron uptake mechanisms, the reductase-permease complex and the siderophore-assisted mechanism. ${ }^{110}$ The latter has been demonstrated in vitro, as holotransferrin, but not apotransferrin, supports the growth of Aspergillus spp. in iron-depleted serum culture systems. In such systems, siderophore production becomes evident following $10 \mathrm{~h}$ of incubation and reaches a peak at $20 \mathrm{~h} .105$ Nevertheless, not all species and strains produce siderophores. Some fungi use ferric reductases or low molecular mass iron reductants, to reduce ferric to ferrous iron, and extract it from the extracellular environment. Such mechanisms have been documented in $C$. albicans, Histoplasma capsulatum, 111 and in Cryptococcus neoformans. 112

\subsection{Iron metabolism in Zygomycetes}

Zygomycosis is a difficult-to-treat systemic fungal infection, caused by the zygomycetes, and is associated with a high mortality rate, ranging from $50 \%$ to $100 \%$. Rhizopus oryzae is the most common cause of zygomycosis. The disease is usually presented with the rhinocerebral form and is characterized by the propensity of zygomycetes for vascular invasion and dissemination, commonly resulting in thrombosis and tissue necrosis. The infection can rapidly extend from the paranasal sinuses to the oral cavity, to the orbit and intracranially, sometimes producing cavernous sinus thrombosis. ${ }^{113}$ Zygomycosis almost always occurs among patients with a pre-existing immune defect, although rare cases have been reported among apparently normal individuals. ${ }^{114}$ In the majority of cases, the course is rapidly progressive and eventually fatal, unless prompt treatment with high doses of liposomal amphotericin B (LAmB), in association with careful and may be repeated surgical debridement, can change the otherwise dismal clinical course.

Since the spectrum of diseases for which the use of immunosuppressive treatments, such as corticosteroids, cyclosporine, purine analogs (fludarabine, cladribine, nelarabin, pentostatin), rapamycin and mTOR inhibitors, various monoclonal antibodies (rituximab, bevacizumab, infliximab, basiliximab, Campath, etc) and allogeneic hematopoietic stem-cell transplantation has enlarged, 115 and since the use of systemic antifungal prophylaxis with agents that are ineffective against zygomycetes, mainly azole derivatives has increased, zygomycosis appears to be an emerging threat the last two decades.116 Well-recognized predisposing factors for zygomycosis are diabetes mellitus (especially when complicated by ketoacidosis), treatment with corticosteroids, immunosuppression, prolonged leukopenia (neutropenia and lymphopenia), recent chemotherapy and tissue damage, history of allogeneic stem cell transplantation, chronic graft-versus-host-disease, and prolonged treatment with broad spectrum antibiotics and azole-type antifungal prophylaxis. 
However, a common denominator of almost all of these conditions is the presence of excessive iron overload, either as high tissue iron burden, or as elevated serum Tf, and also as increased non-transferrin-bound iron. ${ }^{117}$ In particular, it has been suggested that diabetic ketoacidosis and acidoses of any aetiology predispose to zygomycosis by facilitating the dissociation of iron from iron-carrying proteins, thus providing increased available free iron. ${ }^{118}$ Elevated serum and tissue iron have a tremendous impact on the growth and development of zygomycetes. 119 There are reports of fast Mucor growth, with formation of intra-arterial thrombi, among immunocompromised patients with iron overload.120,121 In a retrospective analysis of 263 allotransplanted patients, all five cases of invasive zygomycosis had significantly higher serum ferritin levels, Tf saturation, and number of previously transfused red blood cell units, as compared with matched controls. Zygomycetes possess a specific high-affinity iron permease gene (RFTR1), which has been characterized and cloned.122 Analysis of the polymorphisms of this gene, has recently been proposed as a tool for the molecular identification of the different zygomycete species.123 FTR1 is expressed during infection in diabetic ketoacidosis (DKA) and is required for full virulence of R.oryzae in mice. Disrupted FTR1 in multinucleated R. oryzae resulted in the inability of the fungus to segregate to a homokaryotic null allele. However, reduction of the relative copy number of FTR1-mRNA and inhibition of FTR1 expression by RNAi compromised the ability of $R$. oryzae to acquire iron in vitro and reduced its virulence in DKA mice. Importantly, passive immunization with anti-Ftr1p immune sera protected DKA mice from infection with $R$. oryzae. ${ }^{124}$

The well-documented and repeatedly reported increased susceptibility to zygomycosis of haemodialysis patients, during treatment with DFO, an iron chelator that is capable of removing tissue iron, initially appeared to be a paradox.125,126 It became clear, however, that although DFO chelates iron, from the perspective of zygomycetes it is a xenosiderophore, as fungal siderophores have higher affinity for iron than DFO and therefore, are capable of easily and effectively detaching iron from it and providing it to the fungi. ${ }^{101,126}$ This ability is particularly prominent in zygomycetes, and these species can remove 8-40 times greater amounts of iron from DFO than A. fumigatus and C. albicans, respectively. The rapid and effective iron uptake by zygomycetes results in rapid growth in serum. The growth of Rhizopus rhizopodiformis spores, isolated from a dialysis patient with zygomycosis while on DFO therapy, was studied in an iron-deficient medium, containing human serum at increasing concentrations, enriched with different concentrations of ferrioxamine. A serum concentration of $40 \%$ inhibited fungal growth by $>50 \%$. However, in the presence of serum, ferrioxamine produced significant growth stimulation at $24 \mathrm{~h}$ that persisted at $48 \mathrm{~h}$ (Figure 1). ${ }^{127}$ Data from animal models emphasize the exceptional requirement of iron for Rhizopus pathogenicity, since administration of DFO or free iron worsens the survival of animals infected with Rhizopus, but not with Candida.128 DFO can act as a xenosiderophore in Rhizopus, other members of the Mucorales, and probably other pathogenic fungi. It is assumed that fungal enzymes or siderophores are able to specifically bind to ferrioxamine and, because they have higher affinity for iron, strip iron from ferrioxamine and facilitate iron uptake by the fungi. A similar phenomenon does not take place with deferiprone.129 The susceptibility of dialysis patients, treated with DFO, to zygomycosis could be attributed to the fact that uraemia results in significant retention of the iron-loaded ferrioxamine in the circulation, and that this is removed during dialysis, causing patients' serum to lose its fungistatic power and be transformed to a favourable culture medium for zygomycetes. 130 

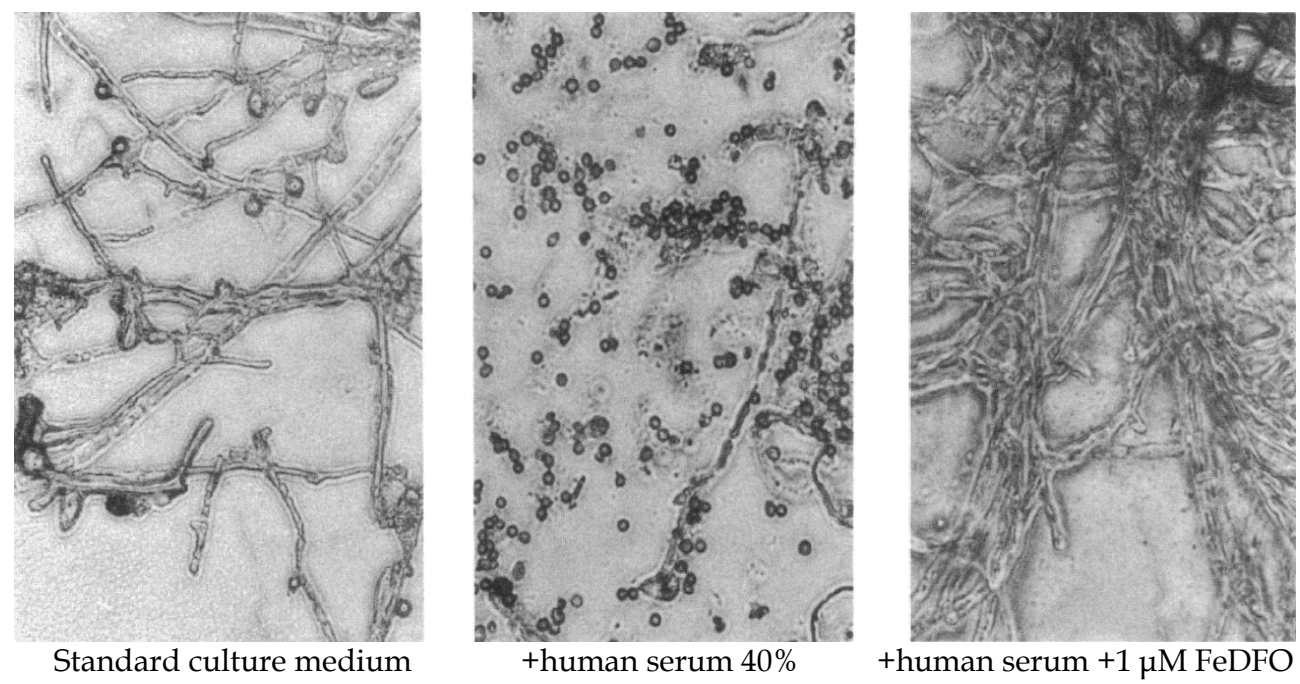

Fig. 1. Spores of Rhizopus were cultivated for $24 \mathrm{~h}$ at 370C in standard culture medium BDM alone (A), in BDM with 40\% human serum (B) or in BDM with $40 \%$ serum $+1 \mathrm{MM}$ Fe.DFO (C). Lugol stain x 500. Reprinted from Boelaert J et al. J.Clin.Invest. 1993; 91: 19791986.

\subsection{The role of newer iron chelators}

Since the mid-90's additional orally administered iron chelators are available. There are two newer molecules, deferiprone (DFP, Ferriprox, Apotex), which was introduced in the 1990s, and deferasirox (DFX, Exjade, Novartis), which was introduced more recently. ${ }^{131}$ Both drugs are effective in clinical practice, but their use has not been associated with increased numbers of fungal infections and particularly, of zygomycosis. The reason for this discrepancy, as compared with DFO, may be the different chemical structure and chelating affinities of the three drugs. DFO is an exadentate chelator, has a higher molecular weight and shows a chelating relationship with the ferric iron of $1: 1$, which implies that each DFO molecule chelates one ferric ion. DFP is a bidentate chelator, and its chelating relationship is $3: 1$, meaning that each ferric iron is chelated by three molecules of DFP. DFX is a tridentate chelator, and its chelating relationship is $2: 1$, meaning that each ferric iron is chelated by two molecules of DFX.132 The chemical structures of the three iron chelators are shown in Figure 2.

The two newer iron chelators do not act as xenosiderophores, apparently because the fungal iron uptake systems are incapable of detaching iron from them. This could be due, either to inadequate molecular access, since they are smaller molecules than DFO, or to their higher affinity for iron, which means that DFP and DFX might form more stable chemical structures with iron, that are not destabilized in the presence of fungal enzymes or siderophores. Moreover, the demonstration of clear inhibitory activity of the two newer chelators on fungal growth suggests that these molecules are probably capable of detaching iron from the fungal iron uptake molecules and holding it more strongly. ${ }^{133}$ This has been proven in vivo, using animal models of zygomycosis, in which treatment of Rhizopus- 


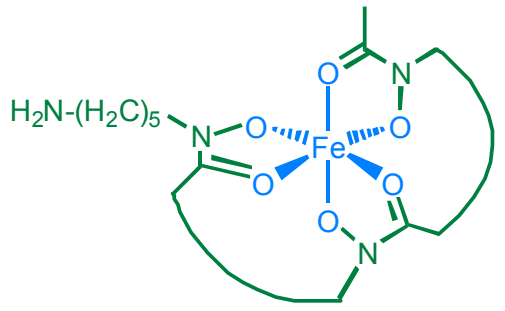

Deferroxamine (DFO)

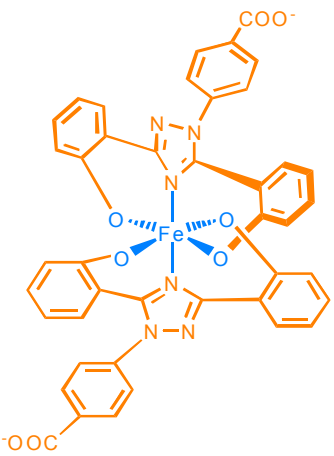

Deferasirox (DFX)

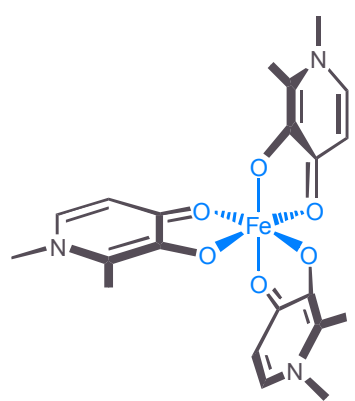

Deferiprone (DFP)

Fig. 2. Stereochemical structure and mocecular chelating relationship of the three available iron chelators. Deferroxamine (DFO) has higher molecular weight (MW) and is a hexadentate, i.e. each molecule holds one ferric iron (chelating ratio 1:1). Deferasirox (DFX) has lower MW and it is a tridentate, i.e. 2 DFX molecules hold each ferric iron (chelating ratio 2:1). Deferiprone (DFP) has even lower MW and it is a bidentate, i.e. 3 DFP molecules chelate each ferric iron (chelating ratio 3:1).

infected mice or guinea pigs with DFP markedly improved survival. ${ }^{133}$ In cultures of Rhizopus oryzae, DFP has fungistatic activity at $24 \mathrm{~h}$, confirmed at $48 \mathrm{~h} .{ }^{129}$ The introduction of DFX and the recognition of the safety and efficacy profile of the drug encouraged its use in sporadic cases of systemic zygomycosis and in experimental animal studies. DFX induces an iron-starvation response in R. oryzae and activates RFTR1 expression. Addition of DFX to cultures of different members of the Mucorales produced a fungicidal effect, which was reversed by the addition of iron. The MIC90s of DFX against various Mucor spp. were much lower than the levels achieved by the administration of the usual daily dose of $20 \mathrm{mg} / \mathrm{kg}$. Treatment with routine doses of DFX of diabetic ketoacidotic mice, infected with spores of $R$. oryzae led to significantly improved survival, as compared with controls, and resulted in a more than ten-fold reduction of brain and kidney fungal burden as compared with placebotreated animals. The kidneys of DFX-treated mice had no visible hyphae and there was an effective neutrophil inflammatory reaction, whereas kidneys of placebo-treated mice had extensive filamentous fungi and manifested a poor or complete absence of a neutrophil inflammatory response. ${ }^{134}$ In another experiment, mice infected intranasally with $10^{7}$ spores of $R$. oryzae were treated for 7 days, starting $24 \mathrm{~h}$ post-infection, with either DFX $10 \mathrm{mg} / \mathrm{kg}$ twice daily or placebo. Similar to controls, infected or uninfected mice were treated with DFO $50 \mathrm{mg} / \mathrm{kg}$. DFX was significantly more protective than placebo or DFO. As expected, DFO worsened the survival of infected mice, although it had no effect on uninfected mice. Treatment with DFX resulted in significantly increased Th1 and Th2 splenocyte subpopulations, and in significantly higher splenic and kidney levels of the proinflammatory cytokines TNF- $\alpha$ and IFN- $\gamma$, than those in mice treated with saturating iron or placebo. ${ }^{134,135}$

\section{Iron, protozoan and parasitic infections}

For the most intracellular protozoa, survival, growth and replication within the phagolysosomes of the macrophages is almost entirely relied on their successful iron 
acquisition from the host cells. These microorganisms elaborate elegant mechanisms for obtaining iron and transfer it into the iron-poor endophagosomal environment.

Legionella pneumophila requires iron for optimal extracellular and intracellular growth. Some mutants are both, sensitive to the iron chelators and resistant to streptonigrin, an antibiotic which requires high levels of intracellular iron to exert microbicidal activity. These mutants were about 100-fold more sensitive than the wild type to treatment with DFO, indicating that they have defective intracellular iron acquisition and assimilation. This strain was unable to mediate any cytopathic effect and was impaired for infectivity of an amoebal host. ${ }^{136}$ L.pneumophila is engulfed into macrophages by macropinocytosis, and is not digested but proliferates intracellularly. Proliferation can be blocked by the Nramp1 protein, an iron transporter that reduces endolysosomal iron and confers resistance against invasive pathogens. However, inactivation of the PI3K pathway enhances Legionella infection and suppresses the protective activity of Nramp1. L.pneumophila abrogates phosphoinositidedependent fusion of macropinosomes with acidic vesicles, without affecting Nramp1 recruitment. Thus Legionella escapes fusion with acidic vesicles and Nramp1-induced resistance to pathogens. ${ }^{137}$

For any protozoan pathogen iron is an absolutely necessary nutrient to effectively grow and multiply. On the other hand many antiparasistic immune effector mechanisms of innate and adaptive immunity are orchestrated through iron deprivation. Incubation of human enterocyte cell lines with IFN- $\gamma$ and in vitro infection with the protozoan enteropathogen Cryptosporidium paroum resulted in the upregulation of IFN- $\gamma$ receptors and was followed by inhibition of the parasite growth and development. IFN- $\gamma$ mediated its action by inhibition of parasite invasion and by modification of intracellular $\mathrm{Fe}^{++}$concentration, and this effect was partially reversed by inhibition of the JAK/STAT signaling pathway. IFN- $\gamma$ directly induces enterocyte resistance against C.paroum infection. ${ }^{138}$

Toxoplasma gondii is an obligate intracellular parasite and a common opportunistic pathogen in HIV positive patients, and macrophage early nonspecific response is an important part of host defense. About $18 \mathrm{~h}$ following infection of mouse macrophages with a high burden of T.gondii tachyzoites, a strong down-regulation of the macrophage Tf receptor levels was observed. Stimulation of the mouse cells with toxoplasma lysate antigen had no effect on Tf receptor expression. ${ }^{139}$ IFN- $\gamma$ alone or in combination with IL-1, IL-6 or TNF-a significantly inhibited T.gondii growth in murine astrocytes. However this inhibition appear not to be mediated through induction of ROS expression, or iron deprivation, but by other, as yet unclear mechanisms. ${ }^{140}$

The in vitro growth of Pneumocystis Carinii can be easily suppressed by daphnetin (7,8dihydroxycoumarin) a well-known iron chelator, through iron deprivation in a dosedependent way. The inhibitory activity is not exerted when iron-repleted daphnetin is added to the culture system. Inhibition of P.carinii growth by daphnetin is associated with morphological changes, clearly determined by transmission electron microscopy. ${ }^{141}$

Leishmania donovani uses another mechanism to obtain iron from the labile iron pool of the macrophages. As a consequence, intracellular macrophage iron is depleted, iron sensor, through IRP- 1 and -2 is activated, mRNA of the Tf receptor- 1 is stabilized and is transcribed, Tf receptor expression is upregulated and Tf uptake is increased. Then Leishmania easily retrieves iron from holotransferrin. ${ }^{142}$ L. donovani itself expresses a Tf receptor and their in 
vitro growth is inhibited by iron chelators. Moreover, in vivo administration of DFO in mice infected with Leishmania leads to a slight delay in the development of cutaneous lesions. Unexpectedly however, systemic iron delivery at early time points of infection, decreased parasite load at the site of parasite inoculation, the regional lymph node, the liver and spleen. The protective effect of iron correlated with lower IL-4 and IL-10, but higher type-1 cytokine transcripts (IFN- $\gamma$ and inducible NO synthase) at the site of inoculation, as well as by increased serum levels of IgG2a. ${ }^{143}$ An iron-dependent superoxide dismutase from Leishmania Chagas is expressed at low levels in the early logarithmic stage of development and increases at later stages of growth. The parasite demonstrates significant growth reduction when endogenous superoxide levels are increased, following the addition of paraquat in culture. There is a protective gene, LcFeSODB, which plays an important role in the parasite growth and survival by protecting the glycosomes from superoxide toxicity. ${ }^{144}$

Malnutrition alters the innate immune response against L.donovani. Thus, diets deficient in calories, protein, and in the metal elements zinc and iron represent a risk factor for the development of visceral leishmaniasis, and in malnourished mice, a greater parasite burden is found in the spleen and liver, which is attributed to a failure of lymph node barrier function. Lymph node cells from the malnourished group produced increased levels of $\mathrm{PGE}_{2}$ and decreased levels of IL-10 and inducible NO synthase activity. ${ }^{145}$ Iron deficiency may finally favor the host and impair L.donovani growth. When iron availability is restricted the parasite's growth may be reduced and the infection attenuated. ${ }^{146}$

Another Leishmania spp, Leishmania amazonensis, elaborates an inducible ferrous iron transport system through LIT1, a novel parasitic membrane protein. LIT1 is only detectable upon intracellular invasion of the parasite and its expression is accelerated under irondeprived conditions. L. amazonensis lacking LIT1 protein abolishes its virulence and its replicating capacity within macrophages. ${ }^{147}$

Trichomonas vaginalis is the most common non viral pathogen, transmitted sexually and is highly-dependent on iron. T. vaginalis is adhered to vaginal epithelial cells, through specific surface proteins (AP65, AP51, AP33 and AP23) named adhesins. Free iron, heme and hemoglobin induce AP65 mRNA and protein expression on the parasistic membrane, thus favoring virulence. Heme-induced AP65 expression was about 10-fold higher in a low-iron culture medium, indicating that $T$. vaginalis can use heme as an alternative source of iron, important to its growth and regulation of expression of the adhesin genes. ${ }^{148}$ An ironresponsive promoter and other iron regulatory elements (IRE) in the 5'-UTR of the ap65-1 gene, as well as two IRE-like hairpin-loop structures in mRNAs of TVCP4 and TVCP12 cysteine proteinases, have been identified in T.vaginalis, suggesting the existence of a posttranscriptional iron regulatory mechanism of critical genes by an IRE/IRP-like system in this protozoon. ${ }^{149} \mathrm{DFO}$ killed all T.vaginalis isolates with a minimum lethal concentration of $30 \mu \mathrm{M}$ after $48 \mathrm{~h}$ of exposure, and a potent and persistent inhibitory effect of DFO on the parasite viability and growth was observed, with lower drug concentration and shorter time of exposure. 150

Tritrichomonas foetus is a protozoan pathogen of cattle, and its growth and virulence is greatly influenced by the iron concentration of the culture medium. In iron-restricted media both, Lf and Tf support T.foetus growth. However, a specific binding to the outer parasitic membrane has been demonstrated only for Lf, whose uptake at $37^{\circ} \mathrm{C}$ is about 3.5-fold higher, a finding indicating a mechanism of receptor-mediated endocytosis. In contrast, Tf 
binding is nonspecific, and iron retrieval is achieved via extracellular release and siderophore assistance. ${ }^{151}$ Many microbial siderophores can also support $T$. foetus growth under iron-limited conditions, providing iron to ferredoxin, the major siderophore of the parasite. Iron uptake is not mediated by previous extracellular reduction, although T.foetus possesses some ferrireductase activity. Siderophores are pinocytosed by the parasites in small vesicles, exhibiting a very acidic environment. Hemin also supports $T$. foetus growth, probably with the involvement of heme oxygenase.152 Parasites grown in iron-depleted media exhibit reduced capability to destroy epithelial cell monolayers and reduced activity of several cysteine proteases, indicating that iron is an extracellular signal, modulating T.foetus' ability to interact with host epithelial cells. ${ }^{153}$ In one study, mice inoculated intraperitoneally with a moderately- or a highly-virulent strain of T.foetus and treated with ferric citrate exhibited high mortality rate by the moderately-virulent strain up to the level of the highly-virulent strain. Peritoneal cultures showed that iron overload was associated with stimulation of parasite replication, which was strongly suppressed in untreated mice, and the less virulent strains showed lower efficiency for iron acquisition from $\mathrm{Tf}$ and other sources. 154

The greatest experience about the influence of iron metabolism on parasite growth has emerged from the study of malaria infection. Plasmodium grows up fluently in the intraerythrocyte environment, where plenty of iron, contained in hemoglobin, can be easily accessed and uptaken. Since about 3 decades ago there has been emerging evidence that, iron deprivation might represent an important mechanism in the battle of man against malaria.155 Asymptomatic parasitemia has been associated with the existence of hypochromic anemia, in the absence of a prominent acute phase reaction. These patients exhibit higher serum hepcidin concentration, higher ferritin, lower iron and transferrin levels, and lower transferrin saturation, and consequently have impaired intestinal iron absorption and dietary iron utilization. On the other hand malaria commonly coexists with a background of frank iron deficiency. Antimalarial treatment partly restores low-grade inflammation and decreases serum hepcidin, ferritin, and other indeces of inflammation, and should be preceded of any effort for anemia correction with iron. Clearance of parasitemia increases dietary iron absorption but did not affect systemic iron utilization. Therefore, in areas of high prevalence of malaria, since asymptomatic parasitemia has a protracted course, careful clinical evaluation of anemic patients is mandatory, because the unjustified or mistimed iron supplementation will be ineffective and may even be hazardous and render malaria symptomatic. 156,157 Among pregnant women in areas with high malaria prevalence, malaria parasitemia, hookworm infection, gravidity and advanced gestational age were associated with lower hemoglobin and iron deficiency. Malaria parasitemia, Ascaris lumbricodes and Trichuris trichiura infections and older age were associated with lower serum ferritin levels. ${ }^{158}$

Intraerythrocytic malaria parasites digest hemoglobin to obtain the amino acids needed for their own protein synthesis. Hemoglobin degradation and total parasite protein content increase in parallel with parasite maturation, but the rate of hemoglobin degradation is higher, than the utilized amount of amino acids. ${ }^{159}$ Hemoglobin degradation yields also large quantities of ferriprotoporphyrin IX and iron, which create a highly oxidative erythrocyte environment and high requirements for detoxification. Redox-active iron released inside the erythrocyte, mediate the conversion of $\mathrm{H}_{2} \mathrm{O}_{2}$ to hydroxyl radical [HO]which is more reactive. Superoxide dismutase (SOD) and nitroxide SOD detoxifies the 
erythrocyte and acts similarly to the antimalarial drug 4-OH,2,2,6,6,tetramethyl piperidine$\mathrm{N}$-oxyl (Tempol) in P.falciparum growth. Tempol inhibits parasite growth, and induces accelerated mortality in a SOD-overexpressing mouse model of malaria.160 SOD has therefore a protective role for the erythrocytes, and transgenic copper/zinc superoxide dismutase- - (CuZnSOD) mouse strains show higher sensitivity to infection by Plasmodium berghei. Moreover, treatment of infected erythrocytes, either SOD transgenic or normal, with oxidative stress inducers, reduces parasite viability. Therefore, $\mathrm{CuZnSOD}$ does not support plasmodium development, and impairment of its activity results in higher oxidative stress, favoring malaria growth. 161

Iron deficiency modulates Plasmodium yoelii development in hepatocytes, by inactivating hepatic xanthine-oxidase. Iron-deficient mice infected with Pl. yoelii sporozoites, exhibited enhanced development of hepatic stage, resulting in the earlier appearance of blood parasites. An iron-starving diet increased penetration of sporozoites into liver cells, whereas inactivation of hepatic xanthine-oxidase inhibited both, sporozoite penetration and schizont maturation. Moreover, inhibition of heme synthesis also results in inhibition of parasite development.162 Another mechanism, favorably influencing the clinical course of Pl.falciparum infection in iron deficient subjects, is the faster clearance of infected erythrocytes. Iron deficiency accelerates unifected erythrocyte death and enhances death and removal of infected erythrocytes by phagocytosis, which is evident from phosphatidylserine exposure. Indeed, parasitized iron deficient erythrocytes are more susceptible to phagocytosis in vitro, than normal erythrocytes. ${ }^{163,164}$ The importance of iron in plasmodium growth has shifted antimalarial treatment strategies and research towards the identification and application of new drugs intervening with the parasite iron metabolism. More details on the topic are mentioned in the following paragraphs.

Trypanosomiasis or Chagas' disease has been associated with iron overload. Trypanosoma possesses a unique mechanism of adaptation and iron acquisition from the host environment. Trypanosoma brucei escapes destruction by the host immune system, by regularly replacing its Variant Surface Glycoprotein (VSG) coat. The VSG is expressed together with expression site associated genes, encoding the heterodimeric Tf receptor. There are about 20 VSG expression sites and trypanosomes can change the active site, according to environmental conditions. Since the various Tf receptor genes, localized in different expression sites, differ somewhat in sequence, expression site switching results in the production of a slightly different Tf receptor. Trypanosomes can adapt the expression site of its Tf receptor to achieve the highest affinity for the host Tf molecule. 165

Hypochromic anemia is a dominant characteristic of this disease and its severity is correlated with the severity of trypanosomiasis. The parasite induces a strong type-I immune response, activating bone marrow and tissue macrophages and establishing an imbalance between erythropoiesis and erythrophagocytosis or erythroblastic apoptosis, which is the typical pathogenetic mechanism of anemia of chronic disease. ${ }^{166}$ In a murine model of trypanosomiasis, erythrophagocytosis by cytokine-activated M1 macrophages was the main initial cause of aggressive anemia during the acute phase of infection. Persistence of type I cytokine production in the chronic phase of infection perpetuates and deteriorates anemia. Meanwhile, iron homeostasis is perturbed and there is increased iron sequestration by macrophages, resulting after upregulation of $\mathrm{Fp}$, Tf and ceruloplasmin genes, indicating that iron export is reduced. In the chronic phase of trypanosomiasis, iron sequestration worsens, while the enhanced uptake of iron-containing molecules is maintained. ${ }^{167}$ 
Entamoeba histolytica trophozoites can grow in vitro within culture media, containing ferrous or ferric iron, and they can use hemoglobin, holotransferrin, hololactoferrin and ferritin as iron sources. Iron-binding proteins are specifically bound to the amoeba surface, are uptaken by endocytosis, traffick through the endosomal/lysosomal route and are degraded by neutral and acidic cysteine-proteases. Tf and ferritin are mainly uptaken as clathrin-coated vesicles. However, apolactoferrin bound to membrane lipids and cholesterol, induces cell death. In vivo trophozoites secrete products capable to destroy enterocytes, erythrocytes and hepatocytes, releasing $\mathrm{Tf}$, hemoglobin, ferritin and other iron-containing proteins, which, together with Lf derived from neutrophils and acinar cells, can be used as iron supplies by amoebas. 168 Many biological functions and pathogenicity of the free-living amoeba Naegleria fowleri are dependent on the composition of the culture medium. The ironcontaining porphyrins hemin or hematin or the iron-free protoporphyrin IX, can support $N$.fowleri growth in serum free media, whereas iron-binding proteins, including hemoglobin cannot.169 Some growth-promoting factors for Entamoeba species are low molecular weight substances, found in cellular fractions of various cells, and are probably siderophores, such as ferredoxins and rubredoxin. 170

Hookworm infection has been associated with growth delay and iron deficiency anemia. In a mouse model of this disease, infected animals, fed with a standard diet exhibited significant growth delay and reduced hemoglobin levels, compared to uninfected controls, whereas no significant difference in weight or hemoglobin concentration was observed between infected and uninfected animals, fed with an iron-restricted diet. Moreover, ironrestricted animals exhibited reduced intestinal worm burden, compared to animals fed with the standard diet. Finally, infected animals fed with intermediate-iron containing diet exhibited greater weight loss and anemia, than animals fed with iron-restricted- or high-iron diets. Mortality was also higher in the intermediate-iron containing diet. Therefore, severe dietary iron restriction impairs hookworm development, but moderate iron restriction enhances host susceptibility to severe disease. ${ }^{171}$

The human blood fluke Schistosoma japonicum is responsible for significant morbidity and mortality in tropical areas. For this fluke and some other invertebrates, an additional role for iron has been postulated, and this concerns the stabilization of the extracellular matrix. Schistosoma requires iron for its development and stores abundant iron in the vitelline (eggshell-forming) cells of the female system, in the form of yolk ferritin that is upregulated in females and is also expressed at low levels in egg-stages and adult males. Iron concentrations have been found higher in the female- than the male adult parasite, but also in the parasite eggs and purified eggshell, whose matrix is composed of heavily cross-linked eggshell precursor proteins. ${ }^{172}$

\section{Clinical considerations - infections in iron overloaded patients}

As previously noted, iron is crucial for the growth and proliferation of all microorganisms, due to its role in mitochondrial respiration and DNA synthesis. Iron starvation and oxidative stress are the hurdles that bacteria must overcome to establish an infection. In some cases there is excess iron available and specific infections are more common. Iron overload may be secondary to lysis of red cells from free heme compounds, as a result of trauma and due to altered metabolism (hemochromatosis, hepatic disease or post chemotherapy). 
In the presence of hemolytic disorders, caused by malaria or Bartonella bacilliformis (in cases of Oroya fever) salmonella infections are noted. ${ }^{173}$ The presence of free hemoglobin or heme may effectively impair or completely destroy the mechanism of natural resistance. Bullen et al. showed that ferric citrate, hematin hydrochloride, lysed guinea-pig red cells and crystalline human hemoglobin greatly enhanced E. coli virulence, when injected intraperitoneally into normal guinea-pigs. ${ }^{174}$

Blood transfusions may increase the free hemoglobin. Red blood cell transfusions should be used sparingly, keeping in mind the potential risks of infection and poor outcomes in critically ill patients. In a prospective, observational cohort study by Taylor et al. the posttransfusion nosocomial infection rate was $14.3 \%$ in 428 evaluable patients, significantly higher than that observed in nontransfused patients $(5.8 \%$; $<0.0001) .{ }^{175}$ In a multivariate analysis controlling for patient age, maximum storage age of red blood cells, and number of red blood cell transfusions, only the number of transfusions was independently associated with nosocomial infection (odds ratio 1.097; $\mathrm{p}=0.005$ ). In addition mortality and length of stay (in intensive care unit and hospital) were significantly higher in transfused patients, even when corrected for illness severity. ${ }^{176}$ Secondary analysis of a multicentered, prospective observational study of transfusion practice in intensive care units in the United States showed that transfusion of packed red blood cells increases the risk of developing VAP (ventilator associated pneumonia). The effect of transfusion on late-onset VAP was more pronounced (odds ratio 2.16; 95\% CI, 1.27-3.66) and demonstrated a positive doseresponse relationship. 177 To determine whether blood transfusion influences infection after trauma, Agarwal et al. analyzed data on 5366 consecutive patients, hospitalized for more than 2 days. Even when patients were stratified by Injury Severity Score, the infection rate increased significantly with the higher numbers of transfused blood units. Blood transfusion in the injured patients is an important independent statistical predictor of infection. Its contribution cannot be attributed to age, sex, or the underlying mechanism of severity of injury. ${ }^{178}$ Both, modified and native human hemoglobin may promote infection. ${ }^{179}$ They showed that pyridoxalated polymerised human hemoglobin promotes fulminant $E$. coli septicemia in mice, which draws attention to the potential danger of such products in the clinic.

Hereditary hemochromatosis is the prototype disease for primary iron overload. Vibrio vulnificus has been linked to primary sepsis, which usually occurs in patients with underlying liver disease (cirrhosis or hemochromatosis). ${ }^{180}$ Although this pathogen can be destroyed by human plasma, it multiplies rapidly when free iron is available. After eating raw sea food, like oysters, the patient develops high fever, prostration, hypotension and in most cases characteristic cutaneous manifestations (initially erythematous patches followed by ecchymoses, vesicles and bullae) with a mortality rate up to $50 \%$ without the prompt therapy. Primary hemochromatosis was the commonest underlying disease in patients with liver abscesses caused by Yersinia enterocolitica. ${ }^{181}$ Some Yersinia strains are unable to synthesize siderophores but they can exploit host-chelated iron stores and the drug DFO. As a result, iron overload appears to be independent risk factor for Y. enterocolitica bacteremia, mainly by the serotypes O:3 and O:9. Yersinia bacteremia must be considered as an indicator of possible iron overload and Yersinia infection must be suspected in febrile hemochromatosic patients. In the past, patients with chronic renal failure, undergoing dialysis received multiple transfusions and frequent parenteral iron preparations. In a study by Boelaer Yersinia bacteremias (Y. enterocolitica and Y. pseudotuberculosis) were detected 
more often when ferritin levels were $>500 \mathrm{ng} / \mathrm{ml} .{ }^{182}$ Y. enterocolitica has also been identified as a causative agent of posttransfusion septic shock. Yersinia bacteremias complicate the transfusions of blood that has been stored for more than 3 weeks. ${ }^{183,184}$ The highpathogenicity island (HPI), present in pathogenic Yersinia and encoding the siderophore yersiniabactin, has been found in E. coli pathotypes, responsible for bacteremias, neonatal meningitis and urosepsis. 185

The spleen, an important part of the reticuloendothelial system, acts as a filter for circulating debris, including bacteria and as an important source of lymphoid cells and antibody production. Splenectomy may alter the ability to prevent or suppress some infections. There appears to be a high risk of severe bacterial infections when splenectomy is performed in patients with thalassaemia major, hepatitis, cirrhosis, histocytosis or inborn errors of metabolism. ${ }^{186,187}$ Seventy three patients with $\beta$-thalassemia/HbE were studied 1-28 years after splenectomy. Serum ferritin levels in both, $\mathrm{HbH}$ and $\beta$-thalassemia/ $\mathrm{Hb} \mathrm{E}$ patients were higher than normal. They were higher in $\beta$-thalassemia/ $\mathrm{HbE}$ than $\mathrm{HbH}$ disease. Most striking was the significantly higher serum ferritin levels in splenectomized patients with $\beta$ thalassemia/ $\mathrm{HbE}$ disease than in the nonsplenectomized ones. After splenectomy, in patients with $\beta$-thalassemia/ $\mathrm{HbE}$ disease, there was an increase of the Tf saturation in addition to increased circulating non-trasferrin bound iron. 188

Levels of serum iron are elevated in patients undergoing hematopoietic stem cell transplantation (HSCT), as a result of disturbed iron metabolism, pre-transplantation blood transfusions, or cytotoxic therapy, for conditioning before HSCT. The complications of iron overload in HSCT patients include bacterial and fungal infections, mucositis, chronic liver disease (fibrosis progression), sinusoidal obstruction syndrome, and other regimen-related toxicities. Iron overload can be considered as an independent adverse prognostic factor in allogeneic HSCT. Screeneing for iron overload at various time points before and after transplantation may be beneficial especially in patients with thalassemia and myelodysplastic syndromes. 189

Singh et al, assessed the role of hepatic explant iron overload as a risk factor for Staph. aureus bacteremia in liver transplant recipients. Noncarriers (patients without $S$. aureus nasal carriage) who developed $S$. aureus bacteremia were more likely to have hepatic iron overload. A quantifiable assessment of hepatic iron in patients without carriage at the time of transplantation can potentially identify those who may be at risk for early $S$. aureus bacteremia. ${ }^{190}$ In healthy humans the lower respiratory tract as well as all mucosa, contains a very low free iron concentration $\left(10^{-18} \mathrm{M}\right)$, while in cystic fibrosis $(\mathrm{CF})$ patients, sputum iron concentration is very high, showing a median value of $63 \times 10^{-6} \mathrm{M}$. Accumulation of catalytic reactive iron contributes to subsequent clinical complications in the lung disorders by the production of ROS and increases bacterial growth and virulence. The iron-overload of the sputum of CF patients induces nonmotile forms, aggregation and biofilm formation both in Pseudomonas aeruginosa and Burkholderia cenocepacia which are the main pathogens in these patients, facilitating the penetration of host epithelial barriers and contributing to the establishment of infection, colonization, persistence and systemic spread of these pathogens.191

In human plasma, a fall in Eh (oxidation-reduction potential) or $\mathrm{pH}$ results in the abolition or marked reduction of its bactericidal properties. This is highly relevant to infection after trauma, where a fall in $\mathrm{Eh}$ and $\mathrm{pH}$ frequently accompanies tissue damage. Hypoxia interferes with the oxidative killing of many bacteria by polymorphonuclear leukocytes. In 
addition it produces a fall in tissue Eh and as a result free ferrous iron is produced, leading to overwhelming growth of bacteria. If the Eh is lowered, the ferric iron is reduced to the ferrous form, no longer bound to Tf.

The bactericidal power of fresh human plasma against Klebsiella pneumoniae and E. coli is extremely sensitive to changes in Eh and pH. At a high Eh (approx. $+200 \mathrm{mV}$ ) the bacteria were destroyed, but rapid regrowth was observed when the Eh was lowered to $-400 \mathrm{mV}$. Abolition of the bactericidal effect was also produced by adding ferric iron at a high Eh (approx. $+200 \mathrm{mV}$ ). Lowering the $\mathrm{pH}$ to 6.5 reduced or prevented the bactericidal effect. Rising the Eh from -400 to $+200 \mathrm{mV}$ restored the bactericidal effect. ${ }^{192}$ Some bacteria like $\mathrm{Cl}$. Perfringens or E. coli have developed reducing systems. They may take advantage of a reduction in skin Eh and they are capable of lowering the Eh of tissue fluids to a level where $\mathrm{Fe}^{2+}$ is freely available. These results are probably related to the availability of iron for bacterial growth, and could be important for understanding the development of infection in injured or diseased tissue. Iron supplementation to treat anemia is controversial, since it may promote the progression of the underlying infectious disease but existing data are insufficient to support this hypothesis. ${ }^{193}$

\section{Iron chelators as adjuvant treatment in systemic fungal and protozoan infections}

It is self-evident if we take into consideration all the above, that an important weapon in the war against the various infectious microorganisms might be iron deprivation. Many efforts have been performed for this task, in targeting the appropriate microbial pathway, identifying the ideal compound for each microorganism, evaluating its efficacy, confirming its safety and testing its clinical usefulness. The usually acute clinical course of bacterial infections, the abundance of antibiotics and the relative satisfactory handling has restricted research programs testing iron chelators for fungal and protozoan infections and infestations.

Among fungal infections the most challenging is zygomycosis, for which effective treatment is still unavailable. Many studies, elaborating animal models for this disease have tried to address the efficacy of iron chelating agents, against this mycosis. In a mouse model of zygomycosis, animals were infected with $R$. oryzae spores, and $24 \mathrm{~h}$ later were treated with DFP at dose levels of 50, 100 or $200 \mathrm{mg} / \mathrm{kg}$ every day or every other day. The dose of 100 $\mathrm{mg} / \mathrm{kg}$ every other day resulted in a significant survival advantage of DFP-treated mice, as compared with placebo-treated animals. The other dose schedules were either ineffective or toxic. The survival advantage was comparable to, although lower than, that of Liposomal Amphotericin-B (LAmB)-treated mice. Both drugs significantly reduced the brain fungal burden as compared with placebo. The beneficial effect of DFP was abrogated when animals were given ferric chloride. ${ }^{133}$ In a similar mouse model of established zygomycosis, the administration of DFX was associated with comparable efficacy to that of LAmB. DFX has shown efficacy in neutropenic and diabetic ketoacidotic mice with zygomycosis. In these experiments, DFX at a daily dose of $20 \mathrm{mg} / \mathrm{kg}$, starting $24 \mathrm{~h}$ after infection was synergistic with LAmB at a high-dose schedule of $15 \mathrm{mg} / \mathrm{kg}$ daily, in the reduction of fungal burden from the brain and the kidney. Moreover, the combination of the two drugs significantly improved survival time as compared with placebo or each drug separately. ${ }^{134}$ Similar results have been obtained with the combination treatment in a mouse model of aspergillosis. ${ }^{135}$ 
The use of iron chelators as adjuvant treatment in systemic zygomycosis and other mycoses appears to be rational, and has been shown to be effective in sporadic cases. Reed et al. reported a case of a 40-year-old diabetic patient with aggressive rhinocerebral zygomycosis and progressive central nervous system involvement, despite combination treatment with high-dose LAmB plus caspofungin and surgical debridement. As brain magnetic resonance imaging (MRI) showed new parenchymal lesions and left cavernous sinus thrombosis, he was given a 7-day salvage treatment with DFX $1000 \mathrm{mg}$ daily. A new brain MRI scan showed significant improvement, and treatment with LAmB was discontinued. The patient, 4 months later, remained in good condition without any neurological deficit. This is the first reported case of zygomycosis being successfully treated with a combination of classical antifungal treatment and an iron chelator. ${ }^{194}$ We have recently treated two patients with acute lymphoblastic leukemia in remission (one of them following allogeneic transplantation) with zygomycosis (one with concurrent rhinocerebral and pulmonary form, the second with classical rhinocerebral form) with a combination of LAmB $10 \mathrm{mg} / \mathrm{kg}$, posaconazole and DFX $20 \mathrm{mg} / \mathrm{kg}$ daily. Restricted intranasal and intrasinus surgical debridement was also applied repeatedly. Both patients responded very well, with rapid defervescence, resolution of pain and chymosis, and disappearance of the dense pulmonary and sinonasal infiltrates (unpublished data). Some more published cases have also shown encouraging results ${ }^{195}$ however in other cases, iron chelation treatment was unsuccessful. 196

Therefore, the possible benefit of iron chelation as adjuvant treatment in systemic mycoses, and particularly in zygomycosis, had to be tested in a prospective randomized trial. Such a clinical trial, the DEFEAT mucor study, investigated the existence of synergy between the classical treatment plus or minus DFX. Twenty patients with proven or probable zygomycosis were randomized to receive LAmB plus DFX $(20 \mathrm{mg} / \mathrm{kg} /$ day for 14 days $)$ or LAmB plus placebo. Surprisingly, death was more frequent in the DFX than in the placebo arm and global success was worse for the DFX arm, since patients of this arm had higher mortality rate at 90 days. This was attributed to population imbalances between the two arms, and therefore, make generalizable conclusions cannot be drawn. ${ }^{197}$

DFO, although is a xenosiderophore for Zygomycetes, may have direct and irreversible toxic effects on P.carinii, independently of iron chelation. This direct and irreversible damage of P.carinii by DFO was confirmed in vivo, in an animal model, in which a once-a-week aerosol treatment of PCP with DFO was effective in $100 \%$ of the animals, both as a prophylactic and as a curative treatment. 198

All the available iron chelators can inhibit the growth of malaria parasites. Using a flow cytometric method for testing in vitro drug susceptibility of Pl.falciparum to hydroxypyridinone derivatives and to DFO, it has been found that both classes of chelators exhibited dose-dependent inhibition of parasite growth, but DFO demonstrated a stronger inhibitory effect. The MIC required for the parasite growth, correlated with observed abnormal microscopic morphology, and sensitivity to iron chelators was shown for both, chloroquine- and pyrimethamine-resistant parasites. ${ }^{199}$ In another study, comparing the efficacy of DFO and DFX at $30 \mu \mathrm{M} / 1$ or $60 \mu \mathrm{M} / 1$, added in cultures of Pl. falciparum in human erythrocytes, it was observed that DFX had marked antimalarial activity by $6 \mathrm{~h}$ after exposure, and over $48 \mathrm{~h}$ of culture, and although the IC50s were similar for DFX and DFO, malarial growth was significantly lower with DFX than with DFO at both concentrations $(\mathrm{P}=0.001) .200$ 
Dexrazoxane is an iron chelating prodrug, used for the protection of anthracyclin-induced cardiotoxicity, which must undergo intracellular hydrolysis to bind iron. Investigating the antimalarial properties of dexrazoxane on Pl. falciparum cultured in human erythrocytes, and on P.yoelii cultured in mouse hepatocytes, it was found that dexrazoxane inhibited $P$. falciparum growth, only at suprapharmacologic concentrations. In contrast, pharmacologic concentrations of dexrazoxane inhibited P.yoelli growth by $45-69 \%$, implying the presence of a dexrazoxane-hydrolyzing enzyme in hepatocytes but not in erythrocytes or malaria parasites.201 Novel aroylhydrazone and thiosemicarbazone iron chelators exhibit strong inhibitory activity on cultured tumor cells. These compounds were tested as antimalarials on chloroquine-sensitive- and -resistant strains of Pl. falciparum, and were significantly more active in both strains than DFO. The anti-malarial activity correlated with anti-proliferative activity against neoplastic cells. This class of lipophilic chelators may be potentially useful agents as anti-malarials. ${ }^{202}$ Among various other synthetic siderophores the most promising profile (low MIC for plasmodia and minimum toxicity to mammalian cells) was demonstrated by an acylated monocatecholate or a triscatecholate as substituent.203 To examine the site of action of antimalarial iron chelators, Loyevsky et al. have shown that specific fluorescence indicating the presence of iron chelators was observed within the parasites, implying that iron chelators bind labile iron within the plasmodium. ${ }^{204}$

The antimalarial activity of zinc-desferrioxamine (Zn-DFO) was found to be superior to that of DFO in vitro. A possible explanation is that the complex Zn-DFO might be more easily permeable into parasitized erythrocytes, exchange zinc for ferric ions due to higher affinity and deprive iron from the parasite. Parasites treated with Zn-DFO were less likely to recover at a later stage, in comparison to parasites treated with DFO, therefore, the complex $\mathrm{Zn}-\mathrm{DFO}$, which is more effective in vitro, should be examined for its in vivo activity. ${ }^{205}$

Many iron chelators are very effective in the treatment of trypanosomiasis and almost as effective as benznidazole, the classical drug used for the treatment of this disease. Some of them inhibit T.Cruzi growth at very low concentrations, thanks to their ability to interfere with and disrupt essential steps of epimastigote iron, copper or zinc metabolism at intracellular sites. ${ }^{206}$ Eleven out of 13 other iron chelators inhibited trypanosoma growth in vitro, but many of these chelators were also cytotoxic for human HL-60 cells and therefore were not further tested. Newer, more specific, lipophilic iron-chelators may serve as lead compounds for novel anti-trypanosomal drug development.207 Bloodstream forms of T.brucei are 10 times more sensitive than mammalian cells to iron depletion, and treatment with DFO inhibits parasite proliferation, inducing inhibition of DNA synthesis and decrease in oxygen consumption, findings implying that DFO impairs ribonucleotide reductase and alternative oxidase activity, apparently by chelating cellular iron and preventing its incorporation into the newly synthesized apoproteins. DFO treatment for $24 \mathrm{~h}$ has no effect on superoxide dismutase activity. ${ }^{208}$ Three compounds of an aminothiol family of iron chelators were tested against Trypanosoma Cruzi. BAT-TE completely arrested the growth of trypomastigote forms in mouse blood, while BAT-TM arrested growth in T.cruzi-infected mice. These results render BAT derivatives potential candidates for the clearing of donated blood from trypomastigotes in endemic areas. ${ }^{209}$

\section{References}

[1] Thelander L, Graslund A, Thelander M. Continual presence of oxygen and iron required for mammalian ribonucleotide reduction: Possible regulation mechanism. Biochem Biophys Res Commun 1983; 110:859-865. 
[2] Weiss G. Modification of iron regulation by the inflammatory response. Best Pract Res Clin Haematol 2005; 18: 183-201.

[3] Aisen P, Enns C, Wessling-Resnick M. (2001) Chemistry and biology of eukaryotic iron metabolism. Int. J. Biochem. Cell Biol. 2001; 33:940-959.

[4] Imlay JA, Chin SM, Linn S. Toxic DNA damage by hydrogen peroxide through the Fenton reaction in vivo and in vitro. Science 1988; 240:640-642.

[5] Gazitt Y, Reddy SV, Alcantara O, Yang J, Boldt DH. A new molecular role for iron in regulation of cell cycling and differentiation of HL-60 human leukemia cells: iron is required for transcription of p21(WAF1/CIP1) in cells induced by phorbol myristate acetate. J Cell Physiol. 2001; 187(1):124-135.

[6] Alcantara O, Kalidas M, Baltathakis I, Boldt DH. Expression of multiple genes regulating cell cycle and apoptosis in differentiating hematopoietic cells is dependent on iron. Exp Hematol. 2001; 29(9):1060-1069.

[7] Dong Fu, Richardson DR. Iron chelation and regulation of the cell cycle: 2 mechanisms of inhibitor p21CIP1/WAF1 by iron depletion post-transcriptional regulation of the universal cyclin-dependent kinase. Blood 2007; 110: 752-761.

[8] Kehrer JP. The Haber-Weiss reaction and mechanisms of toxicity. Toxicology 2000; 149(1):43-50.

[9] Shaw GC, Cope JJ, Li L, Corson K, Hersey C, Ackermann GE et al. Mitoferrin is essential for erythroid iron assimilation. Nature 2006; 440:96-100.

[10] Hentze MW, Muckenthaler MU, Andrews NC. Balancing acts: Molecular control of mammalian iron metabolism. Cell 2004; 117:285-297.

[11] Hentze MW, Kuhn LC. Molecular control of vertebrate iron metabolism: mRNA-based regulatory circuits operated by iron, nitric oxide, and oxidative stress. Proc Natl Acad Sci USA 1996; 93:8175-82.

[12] Napier I, Ponka P, Richardson DR. Iron trafficking in the mitochondrion: Novel pathways revealed by disease. Blood 2005; 105:1867-1874.

[13] Renton FJ, Jeitner TM. Cell cycle-dependent inhibition of the proliferation of human neural tumor cell lines by iron chelators. Biochem Pharmacol 1996; 51:1553-61.

[14] Gao J, Richardson DR. The potential of iron chelators of the pyridoxal isonicotinoyl hydrazone class as effective antiproliferative agents, IV: The mechanisms involved in inhibiting cell-cycle progression. Blood 2001; 98:842-50.

[15] Darnell G, Richardson DR. The potential of analogues of the pyridoxal isonicotinoyl hydrazone class as effective antiproliferative agents, III: the effect of the ligands on molecular targets involved in proliferation. Blood. 1999; 94:781-792.

[16] Kulp KS, Green SL, Vulliet PR. Iron deprivation inhibits cyclin-dependent kinase activity and decreases cyclin D/CDK4 protein levels in asynchronous MDA-MB-453 human breast cancer cells. Exp Cell Res 1996; 229:60-8.

[17] Nurtjahja-Tjendraputra E, Fu D, Phang JM, Richardson DR. Iron chelation regulates cyclin D1 expression via the proteasome: A link to iron deficiency-mediated growth suppression. Blood 2007; 109:4045-54.

[18] Wang G, Miskimins R, Miskimins WK. Regulation of p27(Kip1) by intracellular iron levels. Biometals. 2004; 17(1):15-24.

[19] Lee SH, Pyo CW, Hahm DH, Kim J, Choi SY. Iron-saturated lactoferrin stimulates cell cycle progression through PI3K/Akt pathway. Mol Cells. 2009; 28(1):37-42.

[20] Le NT, Richardson DR. The role of iron in cell cycle progression and the proliferation of neoplastic cells. Biochim Biophys Acta. 2002; 1603(1):31-46.

[21] Triantafyllou A, Liakos P, Tsakalof A, Chachami G, Paraskeva E, Molyvdas PA, Georgatsou E, Simos G, Bonanou S. The flavonoid quercetin induces hypoxia- 
inducible factor-1alpha (HIF-1alpha) and inhibits cell proliferation by depleting intracellular iron. Free Radic Res. 2007; 41(3):342-56.

[22] Schauen M, Spitkovsky D, Schubert J, Fischer JH, Hayashi J, Wiesner RJ. Respiratory chain deficiency slows down cell-cycle progression via reduced ROS generation and is associated with a reduction of p21CIP1/WAF1. J Cell Physiol. 2006; 209(1):103-12.

[23] Ashizuka M, Fukuda T, Nakamura T, Shirasuna K, Iwai K, Izumi $\mathrm{H}$ et al. Novel translational control through an iron-responsive element by interaction of multifunctional protein YB-1 and IRP2. Mol Cell Biol. 2002; 22(18):6375-6383.

[24] Nevitt T. War-Fe-re: iron at the core of fungal virulence and host immunity. Biometals. 2011; 24(3):547-558.

[25] Berlutti F, Pantanella F, Natalizi T, Frioni A, Paesano R, Polimeni A, Valenti P. Antiviral properties of lactoferrin-a natural immunity molecule. Molecules. 2011; 16(8):6992-7018.

[26] Yen CC, Shen CJ, Hsu WH, Chang YH, Lin HT, Chen HL, Chen CM. Lactoferrin: an iron-binding antimicrobial protein against Escherichia coli infection. Biometals. 2011; 24(4):585-94.

[27] Kruzel ML, Actor JK, Radak Z, Bacsi A, Saavedra-Molina A, Boldogh I: Lactoferrin decreases LPS-induced mito-chondrial dysfunction in cultured cells and in animal endotoxemia model. Innate Immun. 2010; 16(2):67-79.

[28] Sandrini SM, Shergill R, Woodward J, Muralikuttan R, Haigh RD, Lyte M, Freestone PP. Elucidation of the mechanism by which catecholamine stress hormones liberate iron from the innate immune defense proteins transferrin and lactoferrin. J Bacteriol. 2010; 192(2):587-594.

[29] Actor JK, Hwang SA, Kruzel ML. Lactoferrin as a natural immune modulator. Curr Pharm Des. 2009; 15:1956-1973

[30] Legrand D, Mazurier J. A critical review of the roles of host lactoferrin in immunity. Biometals. 2010; 23(3):365-376.

[31] Hayworth JL, Kasper KJ, Leon-Ponte M, Herfst CA, Yue D, Brintnell WC et al: Attenuation of massive cytokine response to the staphylococcal enterotoxin $B$ superantigen by the innate immunomodulatory protein lactofer-rin. Clin Exp Immunol. 2009; 157(1):60-70.

[32] Nielsen SM, Hansen GH, Danielsen EM. Lactoferrin targets $T$ cells in the small intestine. J Gastroenterol. 2010; 45(11):1121-1128.

[33] Macedo MF, de Sousa M, Ned RM, Mascarenhas C, Andrews NC, Correia-Neves M. Transferrin is required for early T-cell differentiation. Immunology 2004; 112(4):543-549.

[34] Lucas JJ, Szepesi A, Domenico J, Takase K, Tordai A, Terada N, Gelfand EW. Effects of iron-depletion on cell cycle progression in normal human $\mathrm{T}$ lymphocytes: selective inhibition of the appearance of the cyclin A-associated component of the p33cdk2 kinase. Blood. 1995; 86(6):2268-2280.

[35] Gharagozloo M, Khoshdel Z, Amirghofran Z. The effect of an iron (III) chelator, silybin, on the proliferation and cell cycle of Jurkat cells: a comparison with desferrioxamine. Eur J Pharmacol. 2008; 589(1-3):1-7.

[36] Gupta A, Zhuo J, Zha J, Reddy S, Olp J, Pai A. Effect of different intravenous iron preparations on lymphocyte intracellular reactive oxygen species generation and subpopulation survival. BMC Nephrol. 2010; 11:16.

[37] Kang JL, Lee HS, Jung HJ, Kim HJ. Iron tetrakis (N-methyl-4'-pyridyl) porphyrinato inhibits proliferative activity of thymocytes by blocking activation of p38 mitogen- 
activated protein kinase, nuclear factor-kappaB, and interleukin-2 secretion. Toxicol Appl Pharmacol. 2003; 191(2):147-155.

[38] Gira AK, Casper KA, Otto KB, Naik SM, Caughman SW, Swerlick RA. Induction of interferon regulatory factor 1 expression in human dermal endothelial cells by interferon-gamma and tumor necrosis factor-alpha is transcri-ptionally regulated and requires iron. J Invest Dermatol. 2003; 121(5):1191-1196.

[39] Johnson EE, Sandgren A, Cherayil BJ, Murray M, Wessling-Resnick M. Role of ferroportin in macrophage-mediated immunity. Infect Immun. 2010; 78(12):50995106.

[40] Pinto JP, Dias V, Zoller H, Porto G, Carmo H, Carvalho F, de Sousa M. Hepcidin messenger RNA expression in human lymphocytes. Immunology. 2010; 130(2):217230.

[41] Corna G, Campana L, Pignatti E, Castiglioni A, Tagliafico E, Bosurgi L et al. Polarization dictates iron handling by inflammatory and alternatively activated macrophages. Haematologica 2010; 95(11):1814-1822.

[42] Appelberg R. Macrophage nutriprive antimicrobial mechanisms. J Leukoc Biol. 2006; 79(6):1117-1128.

[43] Kuvibidila SR, Porretta C. Differential effects of iron deficiency on the expression of CD80 and CD86 co-stimulatory receptors in mitogen-treated and untreated murine spleen cells. J Cell Biochem. 2002; 86(3):571-582.

[44] Yildirim K, Karatay S, Melikoglu MA, Gureser G, Ugur M, Senel K. Associations between acute phase reactant levels and disease activity score (DAS28) in patients with rheumatoid arthritis. Ann Clin Lab Sci 2004; 34:423-426.

[45] Lim MK, Lee CK, Ju YS, Cho YS, Lee MS, Yoo B, Moon HB. Serum ferritin as a serological marker of activity in systemic lupus erythematosus. Rheumatol Int 2001; 20:89-93.

[46] Sfagos C, Makis AC, Chaidos A, Hatzimichael EC, Dalamaga A, Kosma K, Bourantas KL. Serum ferritin, transferrin and soluble transferring receptor levels in multiple sclerosis patients. Mult Sclerosis 2005; 11:272-275.

[47] Izawa T, Yamate J, Franklin RJ, Kuwamura M.Abnormal iron accumulation is involved in the pathogenesis of the demyelinating dmy rat but not in the hypomyelinating mv rat. Brain Res. 2010; 1349:105-114.

[48] Hulet SW, Powers S, Connor JR. Distribution of transferring and ferritin binding in normal and multiple sclerotic human brains. J Neurol Sci 1999; 165:48-55.

[49] Levine SM, Maiti S, Emerson MR, Pedchenko TV. Apoferritin attenuates experimental allergic encephalomyelitis in SJL mice. Dev Neurosci 2002; 24:177-183.

[50] Sakata S, Nagai K, Maekawa H, Kimata Y, Komaki T, Nakamura S, Miura K. Serum ferritin concentration in subacute thyroiditis. Metabolism 1991; 40:683-688.

[51] Tran TN, Eubanks SK, Schaffer KJ, Zhou CY, Linder MC. Secretion of ferritin by rat hepatoma cells and its regulation by inflammatory cytokines and iron. Blood 1997; 90(12): 4979-4986.

[52] Fervenza FC, Croatt AJ, Bittar CM, Rosenthal DW, Lager DJ, Leung N et al. Induction of heme oxygenase- 1 and ferritin in the kidney in warm antibody hemolytic anemia. Am J Kidney Dis. 2008; 52(5):972-977.

[53] Blancou P, Tardif V, Simon T, Rémy S, Carreño L, Kalergis A, Anegon I. Immunoregulatory properties of heme oxygenase-1. Methods Mol Biol. 2011; 677:247-268. 
[54] Habel ME, Lemieux R, Jung D. Habel M, Lemieux R, Jung D. Iron specific growth inhibition of Burkitt's lymphoma cells in vitro, associated with a decrease in translocated c-myc expression. J Cell Physiol. 2005; 203(1):277-285.

[55] Kakhlon O, Gruenbaum Y, Cabantchik ZI. Repression of ferritin expression increases the labile iron pool, oxidative stress, and short-term growth of human erythroleukemia cells. Blood 2001; 97(9):2863-2871.

[56] Kadner R. Regulation by Iron: RNA rules the rust. J Bacteriol 2005; 187(20): 6870-6873

[57] Stauff DL, Skaar EP. The heme sensor system (HssRS) of Staphylococcus Aureus. Contrib Microbiol 2009;16: 210-135.

[58] Argandoña M, Nieto JJ, Iglesias-Guerra F, Calderón MI, García-Estepa R, Vargas C. Interplay between iron homeostasis and the osmotic stress response in the halophilic bacterium Chromohalobacter salexigens. Appl Environ Microbiol. 2010; 76(11):3575-3589.

[59] Neiland JB. Siderophores: structure and function of microbial iron transport compounds. J Biol Chem 1995; 270: 26723-26726.

[60] Ferguson AD, Chakraborty R, Smith BS, Esser L, van der Helm D, Deisenhofer J. Structural basis of gating by the outer membrane transporter FecA. Science 2002;295:1715-1719

[61] Ferguson A, Deisenhofer J. Metal import through microbial membrane.Cell 2004; 116: $15-24$.

[62] Krewulak KD, Vogel HJ. Structural biology of bacterial iron uptake. Biochim Biophys Acta. 2008 ;1778(9):1781-804.

[63] Clarke TE, Ku SY, Dougan DR, Vogel HJ, Tari LW. The structure of the ferric siderophore binding protein FhuD complexed with gallichrome. Nat Struct Biol 2000; 7: 287-291.

[64] Goetz M, Bubert A, Wang G, Chico-Calero I, Vazquez-Boland JA, Beck M et al. Microinjection and growth of bacteria in the cytosol of mammalian host cells. Proc Natl Acad Sci U S A. 2001; 98(21):12221-12226.

[65] Borreqaard N, Cowland JB. Neutrophil gelatinase-associated lipocalin, a siderophorebinding eukaryotic protein. Biometals 2006; 19:211-215.

[66] Flo TH, Smith KD, Sato S, Rodriguez DJ, Holmes MA, Strong RK, Akira S, Aderem A. Lipocalin 2 mediates an innate immune response to bacterial infection by sequestrating iron. Nature 2004; 432:917-921.

[67] Fischbach MA, Lin H, Liu DR, Walsh CT. How pathogenic bacteria evade mammalian sabotage in the battle for iron. Nat Chem Biol 2006;2: 132-138.

[68] Müller SI, Valdebenito M, Hantke K. Salmochelin, the long-overlooked catecholate siderophore of Salmonella. Biometals 2009; 22(4):691-695.

[69] Wandersman C, Delepelaire P. Bacterial iron sources: from siderophores to hemophores. Annu Rev Microbiol 2004; 58:611-647.

[70] Perkins-Balding D, Ratliff-Griffin M, and Stojiljkovic I. Iron Transport Systems in Neisseria meningitides. Microbiol Mol Biol Rev 2004; 68(1):154-171.

[71] Nielsen MJ, Møller HJ, Moestrup SK. Hemoglobin and heme scavenger receptors. Antioxid Redox Signal. 2010; 12(2):261-273.

[72] Cescau S, Cwerman H, Létoffé S, Delepelaire P, Wandersman C, Biville F. Heme acquisition by hemophores. Biometals 2007; 20:603-613.

[73] Létoffé S, Redeker V, Wandersman C. Isolation and characterization of an extracellular haem-binding protein from Pseudomonas aeruginosa that shares function and sequence similarities with the Serratia marcescens HasA haemophore. Mol Microbiol. 1998; 28(6):1223-1234. 
[74] Gray-Owen SD, Schryvers AB. Bacterial transferrin and lactoferrin receptors. Trends Microbiol 1996; 4:185-191.

[75] Baysse C, De Vos D, Naudet Y, Vandermonde A, Ochsner U, Meyer JM et al. Vanadium interferes with siderophore-mediated iron uptake in Pseudomonas aeruginosa. Microbiology 2000; 146 (Pt 10):2425-2434.

[76] Mossialos D, Meyer JM, Budzikiewicz H, Wolff U, Koedam N, Baysse C, Anjaiah V, Cornelis P. Quinolobactin, a new siderophore of Pseudomonas fluorescens ATCC 17400 , the production of which is repressed by the cognate pyoverdine. Appl Environ Microbiol. 2000; 66(2):487-492.

[77] Huston WM, Jennings MP, McEwan AG. The multicopper oxidase of Pseudomonas aeruginosa is a ferroxidase with a central role in iron acquisition. Mol Microbiol. 2002; 45(6):1741-1750.

[78] Balado M, Osorio CR, Lemos ML. Biosynthetic and regulatory elements involved in the production of the siderophore vanchrobactin in Vibrio anguillarum. Microbiology 2008; 154(Pt 5): 1400-1413.

[79] Bellmann-Weiler R, Martinz V, Kurz K, Engl S, Feistritzer C, Fuchs D et al. Divergent modulation of Chlamydia pneumoniae infection cycle in human monocytic and endothelial cells by iron, tryptophan availability and interferon gamma. Immunobiology 2010; 215(9-10):842-848.

[80] Mair SM, Nairz M, Bellmann-Weiler R, Muehlbacher T, Schroll A, Theurl I et al. Nifedipine affects the course of Salmonella enterica serovar Typhimurium infection by modulating macrophage iron homeostasis. J Infect Dis. 2011; 204(5):685-694.

[81] López-Goñi I, Moriyón I. Production of 2,3-dihydroxybenzoic acid by Brucella species. Curr. Microbiol 1995; 31:291-293.

[82] González-Carreró MI, Sangari FJ, Agüero J, García Lobo JM. Brucella abortus 2308 produces brucebactin, a highly efficient catecholic siderophore. Microbiology 2002; 148:353-360.

[83] Halling SM, Peterson-Burch BD, Bricker BJ, Zuerner RL, Zing Z, Li LL, Kapur V, Alt DP, Olsen SC. Completion of the gene sequence of Brucella abortus and comparison to the highly similar genomes of Brucella melitensis and Brucella suis. J Bacteriol 2005; 187:2715-2726.

[84] Mills M, Payne SM. Identification of $s h u A$, the gene encoding the heme receptor of Shigella dysenteriae, and analysis of invasion and intracellular multiplication of a shuA mutant. Infect Immun 1997; 65:5358-5363.

[85] Paulley JT, Anderson ES, Martin Roop II R. Brucella abortus requires the heme transporter BhuA for maintenance of chronic infection in BALB/c Mice Infect Immun 2007; 75:5248-5254.

[86] Hentze MW, Muckenthaler MU, AndrewsNC. Balancing acts: molecular control of mammalian iron metabolism. Cell 2004; 117:285-297.

[87] Nemeth E, Tuttle MS, Powelson J, Vaughn MB, Donovan A, Ward DM, Ganz T, Kaplan J. Hepsidin regulates cellular iron efflux by binding to ferroportin and inducing its internalisation. Science 2004; 306:2090-2093.

[88] Appelberg R. Macrophage nutriprive antimicrobial mechanisms. J Leukoc Biol 2006; 79:1117-1128.

[89] Ratledge C. Iron, mycobacteria and tuberculosis.Tuberculosis 2004; 84:110-130.

[90] Rodriguez GM, Voskuil MI, Gold B, Schoolnik GK, Smith I. ideR, an essential gene in Mycobacterium tuberculosis: role of IdeR in iron-dependent gene expression, iron metabolism, and oxidative stress response. Infect Immun 2002; 70:3371-3381. 
[91] Ludwiczek S, Aigner E, Theuri I, Weiss G. Cytokine-mediated regulation of iron transport in human monocyte cells. Blood 2003; 101:4148-4154.

[92] Gomes MS, Boelaert JR, Appelberg R. Role of iron in experimental Mycobacterium avium infection. J Clin Virol. 2001; 20:117-122.

[93] Kahnert A, Seiler P, Sein M, et al. Alternativeactivation deprives macrophages of a coordinated defense program to Mycobacterium tuberculosis. Eur J Immunol 2006; 36:631-647.

[94] Sow FB, Florence WC, Satoskar AR, Schlesinger LS, Zwilling BS, Lafuse WP. Expression and localization of hepcidin in macrophages: a role in host defense against tuberculosis. J Leukoc Biol 2007; 82:934-945.

[95] Sow FB, Alvarez GR, Gross RP, Satoskar AR, Schlesinger LS, Zwilling BS, Lafuse WP. Role of STAT1, NF-kappaB and C/EBPbeta in the macrophage transcriptional regulation of hepsidin by mycobacterial infection and IFN-gamma. J Leukoc Biol 2009;86: 1247-1258.

[96] Weinberg ED. Iron availability and infection. Biochim Biophys Acta. 2009; 1790(7):600605.

[97] Andersson Y, Lindquist S, Lagerqvist C, Hernell O. Lactoferrin is responsible for the fungistatic effect of human milk. Early Hum Dev 2000; 59: 95-105.

[98] Bullen JJ, Griffiths E. Iron binding proteins and host defence. In: Bullen JJ, Griffiths E, eds. 'Iron and infection.' Molecular, physiological and clinical aspects, 2nd ed. Chichester: Wiley, 1999; 327-368.

[99] Halliwell B, Aruoma OI, Mufti G, Bomford A. Bleomycin detectable iron in serum from leukaemic patients before and after chemotherapy. FEBS Lett 1988; 241: 202-204.

[100] Alexander J, Limaye AP, Ko CW, Bronner MP, Kowdley KV. Association of hepatic iron overload with invasive fungal infection in liver transplant recipients. Liver Transpl 2006; 12: 1799-1804.

[101] de Locht M, Boelaert JR, Schneider YJ. Iron uptake from ferrioxamine and from ferrirhizoferrin by germinating spores of Rhizopus microsporus. Biochem Pharmacol 1994; 47: 1843-1850.

[102] Nyilasi I, Papp T, Tako' M, Nagy E, Vagvolgyi C. Iron gathering of opportunistic pathogenic fungi. A mini review. Acta Microbiol Immunol Hung 2005; 52: 185-197.

[103] Ramanan N, Wang Y. A high-affinity iron permease essential for Candida albicans virulence. Science 2000; 288: 1062-1064.

[104] Hsu PC, Yang CY, Lan CY. Candida albicans Hap43 is a repressor induced under lowiron conditions and is essential for iron-responsive transcriptional regulation and virulence. Eukaryot Cell. 2011; 10(2):207-225.

[105] Nevitt T, Thiele DJ. Host iron withholding demands siderophore utilization for Candida glabrata to survive macrophage killing. PLoS Pathog. 2011; 7(3):e1001322.

[106] Tangen KL, Jung WH, Sham AP, Lian T, Kronstad JW. The iron- and cAMP-regulated gene SIT1 influences ferrioxamine $\mathrm{B}$ utilization, melanization and cell wall structure in C. neoformans. Microbiology 2007; 153(Pt 1): 29-41.

[107] Hissen AHT, Wan AN, Warwas ML, Pinto LJ, Moore MM. The Aspergillus fumigatus siderophore biosynthetic gene sidA, encoding L-ornithine N5-oxygenase, is required for virulence. Infect Immun 2005; 73:5493-5503.

[108] Hissen AH, Chow JM, Pinto LJ, Moore MM. Survival of Aspergillus fumigatus in serum involves removal of iron from transferrin: the role of siderophores. Infect Immun 2004; 72:1402-1408. 
[109] Schrett M, Beckmann N, Varga J, Heinekamp T, Jacobsen ID, Jöchl C et al. HapXmediated adaption to iron starvation is crucial for virulence of Aspergillus fumigatus. PLoS Pathog. 2010 Sep 30;6(9):e1001124.

[110] Schrett M, Bignell E, Kragl C et al. Distinct roles for intra- and extracellular siderophores during Aspergillus fumigatus infection. PLoS Pathog 2007; 3: 11951207.

[111] Timmerman MM, Woods JP. Potential role for extracellular glutathione-dependent ferric reductase in utilization of environmental and host ferric compounds by Histoplasma capsulatum. Infect Immun 2001; 69: 7671-7678.

[112] Nyhus K, Wilborn AT, Jacobson ES. Ferric iron reduction by Cryptococcus neoformans. Infect Immun 1997; 65: 434-438.

[113] Anand VK, Alemar G, Griswold JA Jr. Intracranial complications of mucormycosis: an experimental model and clinical review. Laryngoscope 1992; 102: 656-662.

[114] Petrikkos G, Skiada A, Sambatakou H et al. Mucormycosis: ten-year experience at a tertiary-care center in Greece. Eur J Clin Microbiol Infect Dis 2003; 22: 753-756.

[115] Maertens J, Demuynck H, Verbeken EK et al. Mucormycosis in allogeneic bone marrow transplant recipients: report of five cases and review of the role of iron overload in the pathogenesis. Bone Marrow Transplant 1999; 24: 307-312.

[116]Spellberg B, Edwards JJ, Ibrahim A. Novel perspectives on mucormycosis: pathophysiology, presentation, and management. Clin Microbiol Rev 2005; 18: 556569.

[117] Symeonidis A. The role of iron and iron chelators in zygomycosis. Clin Microbiol Infect. 2009; 15(s5): 26-32.

[118] Artis WM, Fountain JA, Delcher HK, Jones HE. A mechanism of susceptibility to mucormycosis in diabetic ketoacidosis: transferrin and iron availability. Diabetes 1982; 31: 1109-1114.

[119] McNab AA, McKelvie P. Iron overload is a risk factor for zygomycosis. Arch Ophthalmol 1997; 115: 919-921.

[120] Kubota N, Miyazawa K, Shoji N et al. A massive intraventricular thrombosis by disseminated mucormycosis in a patient with myelodysplastic syndrome during deferoxamine therapy. Haematologica 2003; 88: EIM13.

[121] Miyata Y, Kajiguchi T, Saito M, Takeyama H. Development of arterial thrombus of Mucorales hyphae during deferoxamine therapy in a patient with aplastic anemia in transformation to myelodysplastic syndrome [in Japanese]. Rinsho Ketsueki 2000; 41: 129-134.

[122] Fu Y, Lee H, Collins M et al. Cloning and functional characterization of the Rhiz. oryzae high affinity iron permease (rFTR1) gene. FEMS Microbiol Lett 2004; 235: 169-176.

[123] Nyilasi I, Papp T, Csernetics A, Krizsa'n K, Nagy E, Va'gvlgyi C. High-affinity iron permease (FTR1) gene sequence-based molecular identification of clinically important Zygomycetes. Clin Microbiol Infect 2008; 14: 393-397.

[124] Ibrahim AS, Gebremariam T, Lin L, Luo G, Husseiny MI, Skory CD et al. The high affinity iron permease is a key virulence factor required for Rhizopus oryzae pathogenesis. Mol Microbiol. 2010; 77(3):587-604.

[125] Boelaert JR, Fenves AZ, Coburn JW. Deferoxamine therapy and mucormycosis in dialysis patients: report of an international registry. Am J Kidney Dis 1991; 18: 660667. 
[126] Kaneko T, Abe F, Ito M, Hotchi M, Yamada K, Okada Y. Intestinal mucormycosis in a hemodialysis patient treated with desferrioxamine. Acta Pathol Jpn 1991; 41: 561566

[127] Boelaert JR, de Locht M, van Cutsem J et al. Mucormycosis during deferoxamine therapy is a siderophore mediated infection: in-vitro and in-vivo animal studies. J Clin Invest 1993; 91: 1979-1986.

[128] Verdonck AK, Boelaert JR, Gordts BZ, Van Landuyt HW. Effect of ferrioxamine on the growth of Rhizopus. Mycoses 1993; 36: 9-12.

[129] Boelaert JR, Van Cutsem J, de Locht M, Schneider YJ, Crichton RR. Deferoxamine augments growth and pathogenicity of Rhizopus, while hydroxypyridinone chelators have no effect. Kidney Int 1994; 45: 667-671.

[130] Verpooten GA, D'Haese PC, Boelaert JR, Becaus I, Lamberts LV, De Broe ME. Pharmacokinetics of aluminoxamine and ferrioxamine and dose finding of deferrioxamine in haemodialysis patients. Nephrol Dial Transplant 1992; 7: 931938.

[131] Neufeld EJ. Oral chelators deferasirox and deferiprone for transfusional iron overload in thalassemia major: new data, new questions. Blood 2006; 107: 3436-3441.

[132] Symeonidis A. The role of iron and iron chelators in zygomycosis. Clin Microbiol Infect. 2009; 15(s5): 26-32.

[133] Ibrahim AS, Edwards JE Jr, Fu Y, Spellberg B. Deferiprone iron chelation as a novel therapy for experimental mucormycosis. J Antimicrob Chemother 2006; 58: 10701073.

[134] Ibrahim AS, Gebermariam T, Fu Y et al. The iron chelator deferasirox protects mice from mucormycosis through iron starvation. J Clin Invest 2007; 117: 2649-2657.

[135] Ibrahim AS, Gebremariam T, French SW, Edwards JE Jr, Spellberg B. The iron chelator deferasirox enhances liposomal amphotericin B efficacy in treating murine invasive pulmonary aspergillosis. J Antimicrob Chemother. 2010; 65(2):289-292.

[136] Pope CD, O'Connell W, Cianciotto NP. Legionella pneumophila mutants, that are defective for iron acquisition and assimilation and intracellular infection. Infect Immun. 1996; 64(2):629-636.

[137] Peracino B, Balest A, Bozzaro S. Phosphoinositides differentially regulate bacterial uptake and Nramp1-induced resistance to Legionella infection in Dictyostelium. J Cell Sci. 2010; 123(Pt 23): 4039-4051.

[138] Pollok RC, Farthing MJ, Bajaj-Elliott M, Sanderson IR, McDonald V. Interferon- $\gamma$ induces enterocyte resistance against infection by the intracellular pathogen Cryptosporidium parvum. Gastroenterology 2001; 120(1):99-107.

[139] Dziadek B, Dytnerska-Dzitko K, Długońska H. The modulation of transferrin receptors level on mouse macropha-ges and fibroblasts by Toxoplasma gondii. Pol J Microbiol. 2004; 53 Suppl:75-80.

[140] Halonen SK, Weiss LM. Investigation into the mechanism of gamma interferonmediated inhibition of Toxoplasma gondii in murine astrocytes. Infect Immun. 2000; 68(6):3426-3430.

[141] Ye B, Zheng YQ, Wu WH, Zhang J. Iron chelator daphnetin against Pneumocystis carinii in vitro. Chin Med J (Engl). 2004; 117(11):1704-1708.

[142] Das NK, Biswas S, Solanki S, Mukhopadhyay CK. Leishmania donovani depletes labile iron pool to exploit iron uptake capacity of macrophage for its intracellular growth. Cell Microbiol. 2009; 11(1):83-94. 
[143] Bisti S, Konidou G, Papageorgiou F, Milon G, Boelaert JR, Soteriadou K. The outcome of Leishmania major expe-rimental infection in BALB/c mice can be modulated by exogenously delivered iron. Eur J Immunol. 2000; 30(12):3732-3740.

[144] Plewes KA, Barr SD, Gedamu L. Iron superoxide dismutases targeted to the glycosomes of Leishmania chagasi are important for survival. Infect Immun. 2003; 71(10):5910-5920.

[145] Anstead GM, Chandrasekar B, Zhao W, Yang J, Perez L, Melby PC. Malnutrition alters the innate immune response and increases early visceralization following Leishmania donovani infection. Infect Immun 2001; 69(8):4709-4718.

[146] Malafaia G, Marcon Lde N, Pereira Lde F, Pedrosa ML, Rezende SA. Leishmania chagasi: effect of the iron deficiency on the infection in BALB/c mice. Exp Parasitol. 2011; 127(3):719-723.

[147] Huynh C, Sacks DL, Andrews NW. A Leishmania amazonensis ZIP family iron transporter is essential for parasite replication within macrophage phagolysosomes. J Exp Med. 2006; 203(10):2363-2375.

[148] Alderete JF, Nguyen J, Mundodi V, Lehker MW. Heme-iron increases levels of AP65mediated adherence by Trichomonas vaginalis. Microb Pathog. 2004; 36(5):263-271.

[149] Torres-Romero JC, Arroyo R. Responsiveness of Trichomonas vaginalis to iron concentrations: evidence for a post-transcriptional iron regulation by an IRE/IRPlike system. Infect Genet Evol. 2009; 9(6):1065-1074.

[150] Mahmoud MS. Effect of the iron chelator deferoxamine on Trichomonas vaginalis in vitro. J Egypt Soc Parasitol. 2002; 32(3):691-704.

[151] Tachezy J, Kulda J, Bahníková I, Suchan P, Rázga J, Schrével J. Tritrichomonas foetus: iron acquisition from lactoferrin and transferrin. Exp Parasitol. 1996; 83(2):216-228.

[152] Sutak R, Chamot C, Tachezy J, Camadro JM, Lesuisse E. Siderophore and haem iron use by Tritrichomonas foetus. Microbiology. 2004; 150(Pt 12):3979-3987.

[153] Melo-Braga MB, da Rocha-Azevedo B, Silva-Filho FC. Tritrichomonas foetus: the role played by iron during parasite interaction with epithelial cells. Exp Parasitol. 2003; 105(2):111-120.

[154] Kulda J, Poislová M, Suchan P, Tachezy J. Iron enhancement of experimental infection of mice by Tritrichomonas foetus. Parasitol Res. 1999; 85(8-9):692-699.

[155] Weinberg ED, Moon J. Malaria and iron: history and review. Drug Metab Rev. 2009; 41(4):644-662.

[156] de Mast Q, Syafruddin D, Keijmel S, Riekerink TO, Deky O, Asih PB et al. Increased serum hepcidin and alterations in blood iron parameters associated with asymptomatic P.falciparum and P.vivax malaria. Haematologica 2010; 95(7):10681074.

[157] Cercamondi CI, Egli IM, Ahouandjinou E, Dossa R, Zeder C, Salami L et al. Afebrile Plasmodium falciparum parasitemia decreases absorption of fortification iron but does not affect systemic iron utilization: a double stable-isotope study in young Beninese women. Am J Clin Nutr. 2010; 92(6):1385-1392.

[158] Ndyomugyenyi R, Kabatereine N, Olsen A, Magnussen P. Malaria and hookworm infections in relation to hemoglobin and serum ferritin levels in pregnancy in Masindi district, western Uganda. Trans R Soc Trop Med Hyg. 2008; 102(2):130-136.

[159] Krugliak M, Zhang J, Ginsburg H. Intraerythrocytic Plasmodium falciparum utilizes only a fraction of the amino acids derived from the digestion of host cell cytosol for the biosynthesis of its proteins. Mol Biochem Parasitol. 2002; 119(2):249-256.

[160] Schwartz E, Samuni A, Friedman I, Hempelmann E, Golenser J. The role of superoxide dismutation in malaria parasites. Inflammation 1999; 23(4):361-370. 
[161] Golenser J, Peled-Kamar M, Schwartz E, Friedman I, Groner Y, Pollack Y. Transgenic mice with elevated level of CuZnSOD are highly susceptible to malaria infection. Free Radic Biol Med. 1998; 24(9):1504-1510.

[162] Goma J, Renia L, Miltgen F, Mazier D. Effects of iron deficiency on the hepatic development of Plasmodium yoelii. Parasite 1995; 2(4):351-356.

[163] Koka S, Föller M, Lamprecht G, Boini KM, Lang C, Huber SM, Lang F. Iron deficiency influences the course of malaria in Plasmodium berghei infected mice. Biochem Biophys Res Commun. 2007; 357(3):608-614.

[164] Matsuzaki-Moriya C, Tu L, Ishida H, Imai T, Suzue K, Hirai M et al. A critical role for phagocytosis in resistance to malaria in iron-deficient mice. Eur J Immunol. 2011; 41(5):1365-1375.

[165] Gerrits H, Mussmann R, Bitter W, Kieft R, Borst P. The physiological significance of transferrin receptor variations in Trypanosoma brucei. Mol Biochem Parasitol. 2002; 119(2):237-247.

[166] Weiss G, Goodnough LT. Anaemia of chronic disease. N Eng J Med 2005; 352:10111023.

[167] Stijlemans B, Vankrunkelsven A, Brys L, Magez S, De Baetselier P. Role of iron homeostasis in trypanosomiasis-associated anemia. Immunobiology 2008; 213(910):823-835.

[168] López-Soto F, León-Sicairos N, Reyes-López M, Serrano-Luna J, Ordaz-Pichardo C, Piña-Vázquez C, Ortiz-Estrada G, de la Garza M. Use and endocytosis of ironcontaining proteins by Entamoeba histolytica trophozoites. Infect Genet Evol. 2009; 9(6):1038-1050.

[169] Bradley SG, Toney DM, Zhang Y, Marciano-Cabral F. Dependence of growth, metabolic expression, and pathogenicity of Naegleria fowleri on exogenous porphyrins. J Parasitol. 1996; 82(5):763-768.

[170] Khalifa SA, Imai E, Kobayashi S, Haghighi A, Hayakawa E, Takeuchi T. Growthpromoting effect on iron-sulfur proteins on axenic cultures of Entamoeba dispar. Parasite 2006; 13(1):51-58.

[171] Held MR, Bungiro RD, Harrison LM, Hamza I, Cappello M. Dietary iron content mediates hookworm pathogenesis in vivo. Infect Immun. 2006; 74(1):289-295.

[172] Jones MK, McManus DP, Sivadorai P, Glanfield A, Moertel L, Belli SI, Gobert GN. Tracking the fate of iron in early development of human blood flukes. Int J Biochem Cell Biol. 2007; 39(9):1646-1658.

[173] Mabey DCW, Brown A, Greenwood BM. Plasmodium falciparum malaria and Salmonella infections in Gambian children. J Infect Dis 1987; 155:1319-1321.

[174] Bullen JJ, Leigh LC, Rogers HJ. The effect of iron compounds on the virulence of Escherichia coli for guinea-pigs. Immunology 1986; 15:581-588.

[175] Taylor RW, Manganaro L, O'Brien J, Trottier SJ, Parkar N, Veremakis C. Impact of allogenic packed red blood cell transfusions on nosocomial infection rates in the critically ill patient. Crit Care Med 2002; 30:2249-2254.

[176] Taylor RW, O'Brien J, Trottier SJ, Manganaro L, Cytron M, Lesko MF et al. Red blood cell transfusions and nosocomial infections in critically ill patients Crit Care Med. 2006;34(9): 2302-2308.

[177] Shorr, AF, Duh MS, Kelly KM, Kolief MH. Red blood cell transfusion and ventillatorassociated pneumonia, a potential link? Crit Care Med 2004; 32:666-674.

[178] Agarwal N, Murphy JG, Cayten CG Stahl WM. Blood transfusion increases the risk of infection after trauma. Arch Surg 1993; 128:171-176. 
[179] Griffiths E, Cortes A, Gilbert N, Stevenson P, MacDonald S, Pepper D. Haemoglobinbased blood substitutes and sepsis. Lancet 1995; 345:158-160.

[180] Chart H, Griffiths E. The availability of iron and the growth of Vibrio vulnificus in sera from patients with haemochromatosis. FEMS Microbiol Lett 1985; 26:227-231

[181] Vadillo M, Corbella X, Pac V, Fernandez-Viladrich P, Pujol R. Multiple liver abscesses due to Yersinia enterocolitica discloses primary hemo chromatosis: three case reports and review. Clin Infect Dis 1994; 18: 938-941.

[182] Boelaert JR, van Landuyt HW, Valcke YJ, et al. The role of iron overload in Yersinia enterocolitica and Yersinia pseudotuberculosis bacteremia in hemodialysis patients. J Infect Dis 1987; 156:384-387.

[183] Leclercq A, Martin L, Vergnes ML, Ounnoughene N, Laran JF, GiraudP, Carniel E. Fatal Yersinia enterocolitica biotype 4 serovar O:3 sepsis after red blood cell transfusion. Transfusion 2005; 45:814-818.

[184] Beresford AM. Transfusion reaction due to Yersinia enterocolitica and review of other reported cases. Pathology 1995; 27(2):133-135.

[185] Clermont O, Bonacorsi S, Bingen E. The Yersinia high-pathogenicity island is highly predominant in virulence-associated phylogenetic groups of Escherichia coli. FEMS Microbiol Lett. 2001; 196:153-157.

[186] Eraklis AJ, Brammer SR, Diamond LK, Gross RE. Hazard of overwhelming infection after splenectomy in childhood. N Engl J Med 1967; 267:1225-1229.

[187] Bishard N, Omari H, Lavi I Raz R. Risk of infection and death among postsplenectomy patients. J Infect 2001; 43(3):182-186.

[188] Pootrakul P, Rugkiatsakul R, Wasi P. Increased transferrin iron saturation in splenectomized thalassaemic patients. Br J Haematol. 1980; 46(1):143-145.

[189] de White T. The role of iron in patients after bone marrow transplantation. Blood Rev 2008; 22(suppl2): S22-28.

[190] Singh N, Wannstedt C, Keyes L, Mayher D, Tickerhoof L, Akoad M et al. Hepatic iron content and the risk of Staphylococcus aureus bacteremia in liver transplant recipients. Prog Transplant 2007; 17(4):332-336.

[191] Berlutti F, Morea C, Battistoni A, Sarli S, Cipriani P, Superti F et al. Iron availability influences aggregation, biofilm, adhesion and invasion of Pseudomonas aeruginosa and Burkholderia cenocepacia. Int J Immunopathol Pharmacol 2005; 18(4): 661-670.

[192] Bullen JJ, Spalding PB, Ward CG, Rogers HJ. The role of Eh, pH, and iron in the bactericidal power of human plasma. FEMS Microbiol Lett 1992; 94: 47-52.

[193] Weiss G. Modification of iron regulation by the inflammatory response. Best Pract Res Clin Haematol 2005;18: 183-201.

[194] Reed C, Ibrahim A, Edwards JE Jr, Walot I, Spellberg B. Deferasirox, an iron-chelating agent, as salvage therapy for rhinocerebral mucormycosis. Antimicrob Agents Chemother 2006; 50: 3968-3969.

[195] Ting JY, Chan SY, Lung DC, Ho AC, Chiang AK, Ha SY et al. Intra-abdominal Rhizopus microsporus infection successfully treated by combined aggressive surgical, antifungal, and iron chelating therapy. J Pediatr Hematol Oncol. 2010; 32(6):e238-240.

[196] Soummer A, Mathonnet A, Scatton O et al. Failure of deferasirox, an iron chelator agent, combined with antifungals in a case of severe zygomycosis. Antimicrob Agents Chemother 2008; 52:1585-1586.

[197] Spellberg B, Ibrahim AS, Chin-Hong PV, Kontoyiannis DP, Morris MI, Perfect JR et al. The Deferasirox-AmBisome Therapy for Mucormycosis (DEFEAT Mucor) study: a 
randomized, double-blinded, placebo-controlled trial. J Antimicrob Chemother. 2011 (in press).

[198] Clarkson AB Jr, Turkel-Parrella D, Williams JH, Chen LC, Gordon T, Merali S. Action of deferoxamine against Pneumocystis carinii. Antimicrob Agents Chemother. 2001; 45(12):3560-3565.

[199] Pattanapanyasat K, Thaithong S, Kyle DE, Udomsangpetch R, Yongvanitchit K, Hider RC, Webster HK. Flow cytometric assessment of hydroxypyridinone iron chelators on in vitro growth of drug-resistant malaria. Cytometry 1997; 27(1):84-91.

[200] Goudeau C, Loyevsky M, Kassim OO, Gordeuk VR, Nick H. Assessment of antimalarial effect of ICL670A on in vitro cultures of Plasmodium falciparum. Br J Haematol. 2001; 115(4):918-923.

[201] Loyevsky M, Sacci JB Jr, Boehme P, Weglicki W, John C, Gordeuk VR. Plasmodium falciparum and Plasmodium yoelii: effect of the iron chelation prodrug dexrazoxane on in vitro cultures. Exp Parasitol. 1999; 91(2):105-114.

[202] Walcourt A, Loyevsky M, Lovejoy DB, Gordeuk VR, Richardson DR. Novel aroylhydrazone and thiosemicarbazone iron chelators with anti-malarial activity against chloroquine-resistant and -sensitive parasites. Int J Biochem Cell Biol. 2004; 36(3):401-407.

[203] Rotheneder A, Fritsche G, Heinisch L, Möllmann U, Heggemann S, Larcher C, Weiss G. Effects of synthetic siderophores on proliferation of Plasmodium falciparum in infected human erythrocytes. Antimicrob Agents Chemother. 2002; 46(6):2010-2013.

[204] Loyevsky M, John C, Dickens B, Hu V, Miller JH, Gordeuk VR. Chelation of iron within the erythrocytic Pl. falciparum parasite by iron chelators. Mol Biochem Parasitol. 1999; 101(1-2):43-59.

[205] Chevion M, Chuang L, Golenser J. Effects of zinc-desferrioxamine on Plasmodium falciparum in culture. Antimicrob Agents Chemother. 1995; 39(8):1902-1905.

[206] Rodrigues RR, Lane JE, Carter CE, Bogitsh BJ, Singh PK, Zimmerman LJ et al. Chelating agent inhibition of Trypanosoma cruzi epimastigotes in vitro. J Inorg Biochem. 1995; 60(4):277-288.

[207] Merschjohann K, Steverding D. In vitro growth inhibition of bloodstream forms of Trypanosoma brucei and Trypanosoma congolense by iron chelators. Kinetoplastid Biol Dis. 2006; 5:3.

[208] Breidbach T, Scory S, Krauth-Siegel RL, Steverding D. Growth inhibition of bloodstream forms of Trypanosoma brucei by the iron chelator deferoxamine. Int J Parasitol. 2002; 32(4):473-479.

[209] Deharo E, Loyevsky M, John C, Balanza E, Ruiz G, Muñoz V, Gordeuk VR. Aminothiol multidentate chelators against Chagas disease. Exp Parasitol. 2000; 94(3):198-200. 


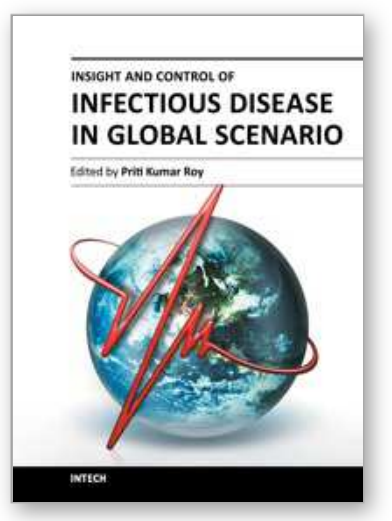

\author{
Insight and Control of Infectious Disease in Global Scenario \\ Edited by Dr. Roy Priti
}

ISBN 978-953-51-0319-6

Hard cover, 442 pages

Publisher InTech

Published online 21, March, 2012

Published in print edition March, 2012

This book is projected as a preliminary manuscript in Infectious Disease. It is undertaken to cover the foremost basic features of the articles. Infectious Disease and analogous phenomenon have been one of the main imperative postwar accomplishments in the world. The book expects to provide its reader, who does not make believe to be a proficient mathematician, an extensive preamble to the field of infectious disease. It may immeasurably assist the Scientists and Research Scholars for continuing their investigate workings on this discipline. Numerous productive and precise illustrated descriptions with a number of analyses have been included. The book offers a smooth and continuing evolution from the principally disease oriented lessons to a logical advance, providing the researchers with a compact groundwork for upcoming studies in this subject.

\title{
How to reference
}

In order to correctly reference this scholarly work, feel free to copy and paste the following:

Argiris Symeonidis and Markos Marangos (2012). Iron and Microbial Growth, Insight and Control of Infectious Disease in Global Scenario, Dr. Roy Priti (Ed.), ISBN: 978-953-51-0319-6, InTech, Available from:

http://www.intechopen.com/books/insight-and-control-of-infectious-disease-in-global-scenario/the-role-of-ironin-fungal-growth-iron-chelation-as-a-targeted-treatment-for-systemic-fungal-infecti

\section{INTECH}

open science | open minds

\author{
InTech Europe \\ University Campus STeP Ri \\ Slavka Krautzeka 83/A \\ 51000 Rijeka, Croatia \\ Phone: +385 (51) 770447 \\ Fax: +385 (51) 686166 \\ www.intechopen.com
}

\author{
InTech China \\ Unit 405, Office Block, Hotel Equatorial Shanghai \\ No.65, Yan An Road (West), Shanghai, 200040, China \\ 中国上海市延安西路65号上海国际贵都大饭店办公楼405单元 \\ Phone: +86-21-62489820 \\ Fax: +86-21-62489821
}


(C) 2012 The Author(s). Licensee IntechOpen. This is an open access article distributed under the terms of the Creative Commons Attribution 3.0 License, which permits unrestricted use, distribution, and reproduction in any medium, provided the original work is properly cited. 